\title{
Archival processes of the water stable isotope signal in East Antarctic ice cores
}

\author{
Mathieu Casado ${ }^{1,2, a}$, Amaelle Landais ${ }^{1}$, Ghislain Picard ${ }^{3}$, Thomas Münch ${ }^{4,5}$, Thomas Laepple ${ }^{4}$, Barbara Stenni ${ }^{6}$, \\ Giuliano Dreossi $^{6}$, Alexey Ekaykin ${ }^{7,8}$, Laurent Arnaud ${ }^{3}$, Christophe Genthon ${ }^{3}$, Alexandra Touzeau ${ }^{1}$, \\ Valerie Masson-Delmotte ${ }^{1}$, and Jean Jouzel ${ }^{1}$ \\ ${ }^{1}$ Laboratoire des Sciences du Climat et de l'Environnement - IPSL, UMR 8212, \\ CEA-CNRS-UVSQ-UPS, Gif-sur-Yvette, France \\ ${ }^{2}$ Université Grenoble Alpes/CNRS, LIPHY, 38000 Grenoble, France \\ ${ }^{3}$ Université Grenoble Alpes/CNRS, LGGE, 38400 Grenoble, France \\ ${ }^{4}$ Alfred Wegener Institute Helmholtz Centre for Polar and Marine Research, Telegrafenberg A43, 14473 Potsdam, Germany \\ ${ }^{5}$ Institute of Physics and Astronomy, University of Potsdam, Karl-Liebknecht-Str. 24/25, 14476 Potsdam, Germany \\ ${ }^{6}$ DAIS, Ca'Foscari University of Venice, Venice, Italy \\ ${ }^{7}$ Arctic and Antarctic Research Institute, St. Petersburg, Russia \\ ${ }^{8}$ Institute of Earth Sciences, St. Petersburg State University, Russia \\ ${ }^{a}$ now at: Alfred Wegener Institute Helmholtz Centre for Polar and Marine Research, \\ Telegrafenberg A43, 14473 Potsdam, Germany
}

Correspondence: Mathieu Casado (mathieu.casado@gmail.com)

Received: 31 October 2017 - Discussion started: 3 November 2017

Revised: 20 April 2018 - Accepted: 21 April 2018 - Published: 24 May 2018

\begin{abstract}
The oldest ice core records are obtained from the East Antarctic Plateau. Water isotopes are key proxies to reconstructing past climatic conditions over the ice sheet and at the evaporation source. The accuracy of climate reconstructions depends on knowledge of all processes affecting water vapour, precipitation and snow isotopic compositions. Fractionation processes are well understood and can be integrated in trajectory-based Rayleigh distillation and isotopeenabled climate models. However, a quantitative understanding of processes potentially altering snow isotopic composition after deposition is still missing. In low-accumulation sites, such as those found in East Antarctica, these poorly constrained processes are likely to play a significant role and limit the interpretability of an ice core's isotopic composition.

By combining observations of isotopic composition in vapour, precipitation, surface snow and buried snow from Dome C, a deep ice core site on the East Antarctic Plateau, we found indications of a seasonal impact of metamorphism on the surface snow isotopic signal when compared to the initial precipitation. Particularly in summer, exchanges of water
\end{abstract}

molecules between vapour and snow are driven by the diurnal sublimation-condensation cycles. Overall, we observe in between precipitation events modification of the surface snow isotopic composition. Using high-resolution water isotopic composition profiles from snow pits at five Antarctic sites with different accumulation rates, we identified common patterns which cannot be attributed to the seasonal variability of precipitation. These differences in the precipitation, surface snow and buried snow isotopic composition provide evidence of post-deposition processes affecting ice core records in low-accumulation areas.

\section{Introduction}

Ice is a natural archive of past climate variations. Its physicochemical composition, including trapped air bubbles, is used as paleoclimate proxies (Jouzel and Masson-Delmotte, 2010, and references therein). The water isotopes in ice cores collected over large ice sheets permit reconstructions of past temperatures as far back as the last glacial period in West 
Antarctica (up to 60000 years ago) (WAIS Divide Project members, 2013) and the last interglacial period in Greenland (120000 years ago) (North Greenland Ice Core Project members, 2004; NEEM Community members, 2013). In East Antarctica, low accumulation rates permit past climate reconstructions spanning several interglacial periods, e.g. 420000 years at Vostok (Petit et al., 1999), 720000 years at Dome F (Kawamura et al., 2017) and 800000 years at Dome C (EPICA, 2004, 2006). While reconstructions from ice cores from Greenland and West Antarctica may not extend as far into the past as from East Antarctica, highresolution analyses of the Greenland and West Antarctica cores provide very fine temporal resolution from which the seasonal cycle can be resolved (Vinther et al., 2010; Markle et al., 2017). Seasonal variations can also be retrieved from snow isotopic compositions at high-accumulation sites in Antarctica's coastal areas (Morgan, 1985; Masson-Delmotte et al., 2003; Küttel et al., 2012). In contrast, the academic community is still debating whether data from lowaccumulation sites on the East Antarctic Plateau can ever yield temporal resolutions finer than multidecadal (Baroni et al., 2011; Ekaykin et al., 2002; Pol et al., 2014; Münch et al., 2016). Ekaykin et al. (2002) analysed multiple pits from Vostok and identified large spatiotemporal variations caused by post-deposition processes associated with surface topography and wind interactions. Such phenomena create a degree of noise that is unrelated to past climatic conditions and could be alleviated by stacking different isotopic composition profiles from several snow pits to reveal the underlying climatic signal. Nevertheless, isotopic analyses of both the precipitation and surface snow data from the East Antarctic Plateau revealed a clear seasonal cycle (Fujita and Abe, 2006; Landais et al., 2012; Stenni et al., 2016; Touzeau et al., 2016). Thus an important open question that needs to be addressed is whether this seasonal cycle is indeed archived in buried snow and whether stacking an array of snow pits sufficiently increases the signal-to-noise ratio to finally resolve those intra-annual timescales (Ekaykin et al., 2014; Altnau et al., 2015; Münch et al., 2016, 2017).

Several studies examined how the climatic signal is archived in the isotopic composition of snow and ice from the East Antarctic Plateau. Since the early works of Dansgaard (1964) and Lorius et al. (1969), the relationship between ice isotopic composition and local temperature has been attributed to distillation as an integrative process associated with successive condensation events occurring between the initial evaporation site and the deposition site (Criss, 1999). Nevertheless, the relationship between isotopic composition and surface temperature is not constant through time and space, due notably to processes within the local boundary layer (Krinner et al., 1997), the seasonality of the precipitation between glacial and interglacial periods (Sime et al., 2009) and variations in air mass transport trajectories (Delaygue et al., 2000; Schlosser et al., 2004) and in the source evaporation conditions (Vimeux et al., 1999). For
East Antarctica, the glacial-interglacial isotope-temperature relationship appears quite close to the spatial gradient, but its validity for interannual variations (Schmidt et al., 2007) and warmer than present-day conditions (Sime et al., 2009) is unclear.

In addition, under the exceptionally cold and dry conditions of East Antarctic drilling sites, contributions of postdeposition processes to the snow isotopic composition cannot be neglected at the atmosphere-snow interface (Town et al., 2008; Sokratov and Golubev, 2009). Indeed, the relationship between temperature and isotopic composition of surface snow is different from the one found in precipitation (Touzeau et al., 2016). It has been recently evidenced that summer exchanges between snow and water vapour significantly affect the isotopic composition of the snow both in Greenland (Steen-Larsen et al., 2014) and on the East Antarctic Plateau (Ritter et al., 2016). In this study, we intend to evaluate the different contributions to the snow isotopic composition signal in order to explain how the climatic signal gets archived. We chose Dome $\mathrm{C}$ as an open-air laboratory to study the different contributions to the surface snow isotopic composition, including (1) direct precipitation input, (2) blowing snow, (3) exchanges with atmospheric vapour and (4) exchanges with the firn below the surface (Fig. 1). Point (3) includes both sublimation and condensation (both liquid and solid condensation). The term "deposition" will refer to the deposition of precipitation and rime at the snow surface leading to accumulation. Point (4) includes several processes such as sublimation in warmer areas of the firn, molecular diffusion in the porosity sometimes enhanced by wind pumping and solid condensation in colder areas of the firn. Point (4) can also be associated with metamorphism (coarsening of the snow grains as a result of temperature gradients in the firn), in which case the impact on the isotopic signal is similar to "isotopic diffusion" such as described by Johnsen (1977). Throughout the paper, the notations used in Fig. 1 will be used to describe the isotopic composition of which type of snow is described.

Since Dome $\mathrm{C}$ is far along the distillation path, only small amounts of precipitable water are available (Ricaud et al., 2014), leading to sparse and irregular precipitation events (Genthon et al., 2015). As a result, snow does not accumulate homogeneously at Dome $\mathrm{C}$, but the deposition is patchy and strongly dependent on the surface roughness (Groot Zwaaftink et al., 2013; Libois et al., 2014; Picard et al., 2016a). A small but significant contribution to the annual mass balance thus comes from sublimation-condensation directly at the surface (Genthon et al., 2017). While negative sublimation fluxes up to $-0.3 \mathrm{~mm}$ w.e. month $^{-1}$ are observed during the austral summer, in the austral winter fluxes are positive with up to $0.1 \mathrm{~mm}$ w.e. month $^{-1}$ and are associated with condensation (vapour-ice phase transitions with or without a liquid intermediary). At Dome C, these contributions constitute up to $10 \%$ of the total annual accumulation; while this may appear small, we expect a significant impact 


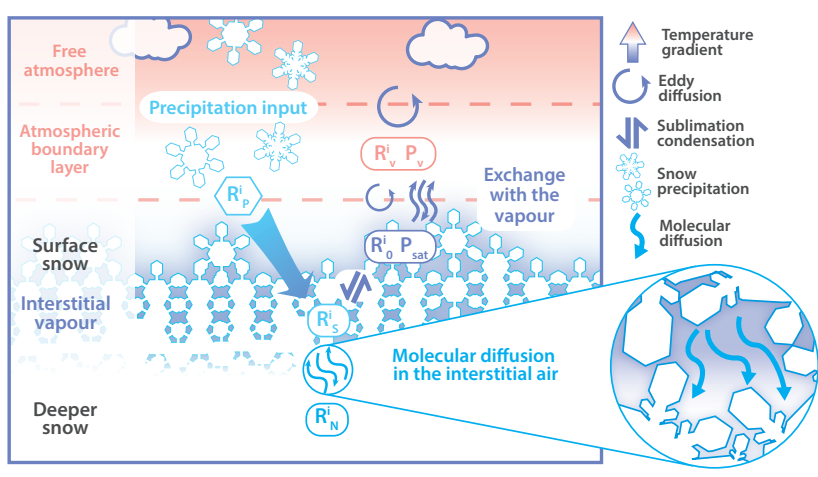

Figure 1. Schematic of the different contributions to snow isotopic composition ( $R_{X}^{i}$ stands for the composition of isotope $i$ in phase $X$ : $P$ is precipitation, $V$ is vapour, $S$ is surface snow, $N$ is the deeper snow, 0 is vapour at equilibrium with the snow and $P_{\mathrm{V}}$ and $P_{\text {sat }}$ are the water vapour partial pressure and the saturated vapour pressure, respectively). Above the surface, both the precipitation and the sublimation-condensation cycles can contribute to the surface composition; in the open-porous firn below the surface, ice crystals can exchange with the air through the pores and may be influenced by wind pumping. Deeper in the firn, molecular diffusion in the interstitial air affects the snow isotopic composition.

on the snow isotopic budget. Indeed, the alternation of negative and positive fluxes would overall have a small mass budget (symmetric mass balance). However, as the temperature is lower during the austral winter when positive fluxes are observed than during the austral summer when the negative fluxes are observed, the isotopic budget is affected by different isotopic fractionation for positive-negative flux periods (asymmetric mass balance).

A diurnal temperature asymmetry is also observed in summer with differentials reaching up to $16^{\circ} \mathrm{C}$ and vapour isotopic composition is directly affected by this differential impacting the (nighttime) condensation and (daytime) sublimation cycle (Casado et al., 2016; Ritter et al., 2016). As the sublimation phase is characterised with higher temperature than the condensation phase, the diurnal cycle also results in an asymmetric isotopic budget. In addition, atmospheric boundary layer dynamics differ between day and night with active daytime convection, leading to turbulence mixing throughout the boundary layer while boundary layer is more stably stratified at night (Casado et al., 2016; Vignon et al., 2017).

Isotope exchanges during snow metamorphism and diffusion within the porous matrix of the subsurface snowpack additionally affect snow isotopic composition (Langway, 1970; Johnsen, 1977; Whillans and Grootes, 1985; Calonne et al., 2015; Ebner et al., 2017) and the diffusion length depends on the firn ventilation, the snow density, porosity and tortuosity and the exchange rate between the atmospheric water vapour and the surface snow (Johnsen et al., 2000; Gkinis et al., 2014). This large variety of processes hampers isotopic signal interpretation. In particular, the degree to which the

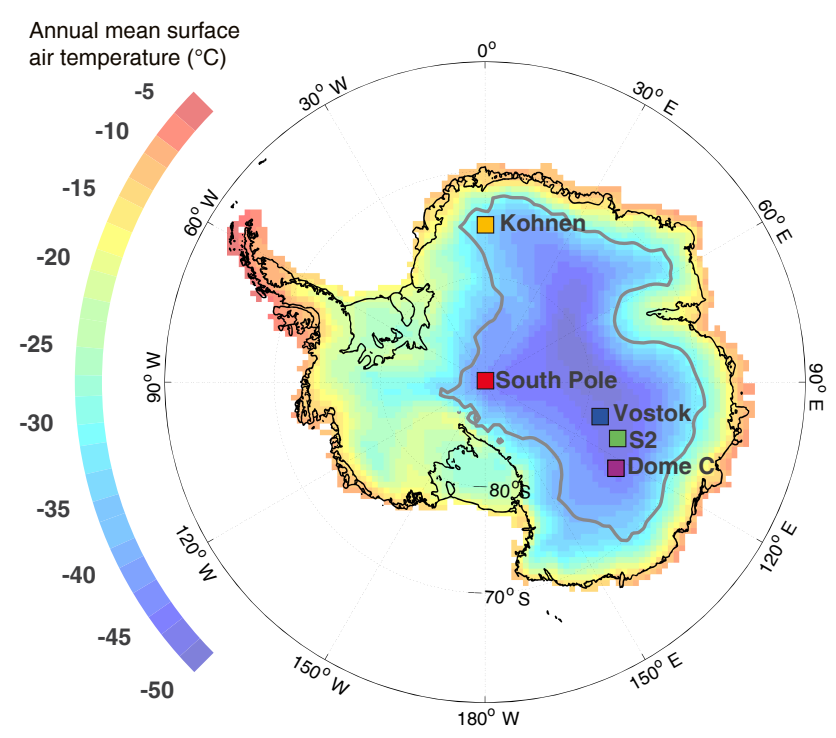

Figure 2. Map of Antarctica showing the East Antarctic Plateau (grey line is the contour of $2500 \mathrm{~m}$ a.s.l.) indicating the location of the sampling sites (solid squares). Colours indicate the annual mean surface air temperature at $2 \mathrm{~m}$ modified from the ERA-Interim dataset from 1979 to 2009 (Nicolas and Bromwich, 2014).

original signal acquired during the evaporation at the moisture source and the formation of the precipitation is preserved during the burial of the snow is unknown (Münch et al., 2017).

Recent studies on the East Antarctic Plateau focused on (1) monitoring the isotopic composition of the snowpack (Touzeau et al., 2016), the precipitation (Fujita and Abe, 2006; Landais et al., 2012; Stenni et al., 2016) and the atmospheric water vapour (Casado et al., 2016; Ritter et al., 2016) and (2) exploring their links to climatic parameters and snow isotopic composition. This study examines the isotopic composition along the continuum such as atmospheric vapour, precipitation, surface and buried snow. By combining existing and new datasets from Dome $\mathrm{C}$ on the East Antarctic Plateau, we performed qualitative characterisation of the different processes affecting surface snow isotope composition on timescales that range from diurnal to annual.

\section{Material and methods}

\subsection{Study sites}

The East Antarctic Plateau lies at $2500 \mathrm{~m}$ above sea level (m a.s.l.) covered with snow and ice spreading across most of the eastern continental part of Antarctica (Fig. 2). It is characterised by mean annual temperatures below $-30^{\circ} \mathrm{C}$ and accumulation of less than $80 \mathrm{~kg} \mathrm{~m}^{-2} \mathrm{yr}^{-1}$ (Fig. 2).

This study mainly focuses on Dome $\mathrm{C}$, the site of the permanent station Concordia, which provides an opportunity for year-long sampling to study the entire seasonal cycle of iso- 
Table 1. Climatic conditions at the different study sites (Alley, 1980; Petit et al., 1982; Wendler and Kodama, 1984; Oerter et al., 2000; Ekaykin et al., 2002; van As et al., 2007; Lazzara et al., 2012; Casey et al., 2014; Genthon et al., 2015; Touzeau et al., 2016; Laepple et al., 2016)

\begin{tabular}{|c|c|c|c|c|c|c|}
\hline Site & Location & $\begin{array}{l}\text { Altitude } \\
\text { (ma.s.1.) }\end{array}$ & $\begin{array}{r}\text { AWS mean } \\
\text { temperature }\left({ }^{\circ} \mathrm{C}\right)\end{array}$ & $\begin{array}{r}10 \mathrm{~m} \text { firn } \\
\text { temperature }\left({ }^{\circ} \mathrm{C}\right)\end{array}$ & $\begin{array}{l}\text { Accumulation } \\
\left(\mathrm{kg} \mathrm{m}^{-2} \mathrm{yr}^{-1}\right)\end{array}$ & $\begin{array}{r}\text { Mean wind } \\
\text { speed }\left(\mathrm{m} \mathrm{s}^{-1}\right)\end{array}$ \\
\hline Kohnen & $75.0^{\circ} \mathrm{S}-0.1^{\circ} \mathrm{E}$ & 2892 & -42.2 & -44.5 & $62-73$ & 4.5 \\
\hline Vostok & $78.5^{\circ} \mathrm{S}-106.8^{\circ} \mathrm{E}$ & 3488 & -55.2 & -57 & 21 & 5.1 \\
\hline $\mathrm{S} 2$ & $76.3^{\circ} \mathrm{S}-120^{\circ} \mathrm{E}$ & 3229 & NA & -55.1 & 21 & NA \\
\hline Dome C & $75.1^{\circ} \mathrm{S}-123.3^{\circ} \mathrm{E}$ & 3233 & -52.4 & -54.3 & 27 & 3.3 \\
\hline South Pole & $90^{\circ} \mathrm{S}-0^{\circ} \mathrm{E}$ & 2835 & -49.3 & -50.8 & 80 & 4.1 \\
\hline
\end{tabular}

topic composition. This site is characterised by low accumulation $\left(27 \mathrm{~mm}\right.$ w.e. year $\left.{ }^{-1}\right)$ and low temperatures $\left(-52.4^{\circ} \mathrm{C}\right)$. To provide a context for the situation of Dome $\mathrm{C}$, we present the conditions found at Dome $\mathrm{C}$ compared to other deep ice core sites on the East Antarctic Plateau: Kohnen, Vostok and Amundsen-Scott South Pole stations and the point S2, which is one of the drilling sites of the campaign Explore-Vanish between Dome C and Vostok (see Fig. 2). These locations span a large range of climatic conditions of the East Antarctic Plateau as illustrated on Table 1.

\subsection{Surface snow and precipitation sampling}

In this study, we analyse water isotopes from precipitation and surface snow sampled by several teams at Dome $\mathrm{C}$ since 2008, employing different sampling protocols (Table 2). We reiterate the different protocols here as they might affect our results.

For the 2011 campaign (SUNITEDC), the top 1 to $5 \mathrm{~mm}$ of snow from $20 \times 20 \mathrm{~cm}$ patches was sampled from randomly selected flat sampling sites (Touzeau et al., 2016).

For the NIVO project (from 2013 to 2016), the top $15 \mathrm{~mm}$ of snow from $20 \times 10 \mathrm{~cm}$ patches was sampled from randomly chosen areas in a 100 by $100 \mathrm{~m}^{2}$ with concurrent density and specific surface area (SSA) (see Sect. 2.4). Spatial variability was accounted for by simultaneously collecting two samples 10 to $50 \mathrm{~m}$ apart. In addition, regular samplings of the surface $(0-3 \mathrm{~cm})$ and subsurface $(3-6 \mathrm{~cm})$ snow were performed daily for almost 2 months during the summer of 2013/14. Additional bi-diurnal samplings took place between December 2014 and January 2015 as part of the GLACIOLOGIE program (see Sect. 2.4 and Casado et al., 2016) following the NIVO protocol $(15 \mathrm{~mm}$ samples gathered directly in the snow).

Between 2008 and 2011, for the PRE-REC program, surface snow and precipitation samples were collected from a $80 \times 120 \mathrm{~cm}$ wooden plate placed at ground level for the surface snow and standing $1 \mathrm{~m}$ above the ground for the precipitation (Stenni et al., 2016). The use of a wooden surface limits mixing with the snow below (both mechanical mixing of snow layers and diffusion-metamorphism) and represents the main difference compared to the other sampling methods.
The comparison of the two sampling methods is provided in Sect. 3.1.2.

\subsection{Snow pits sampling}

Apart from already published snow pit data (Table 3), we present profiles of isotopic composition sampled in snow pits at Dome C: two unpublished profiles from the first preliminary campaign at Dome $\mathrm{C}$ in 1978 and two new snow pit profiles from 2014/15 named P09-2015 and P17-2015, dug $50 \mathrm{~m}$ apart in combination with surface snow sampling and vapour monitoring. For the snow pit P09-2015, snow temperature and density profiles were established. Snow samples for isotopic analysis were taken in airtight plastic flasks.

To extend the results to other sites of the East Antarctic Plateau, we compare the isotopic profiles to other snow pit samplings performed through several campaigns over different sites of East Antarctica which were realised and analysed by different teams (see Fig. 2). In addition to the Dome $\mathrm{C}$ snow pits, two new isotopic composition profiles from Kohnen were extracted from trenches, following the methodology reported in Münch et al. (2016) but up to a depth of $3.6 \mathrm{~m}$ and a vertical resolution of $3 \mathrm{~cm}$.

A large number of snow pits from Vostok station are presented here as well, which were previously described in Ekaykin et al. $(2002,2004)$ and Ekaykin and Lipenkov (2009). We combine the results from six snow pits with depths varying from 2.5 to $12 \mathrm{~m}$ and a minimum resolution of $5 \mathrm{~cm}$. In addition, snow pits from the Explore-Vanish campaign are included comprising one $3.5 \mathrm{~m}$ deep snow pit from Vostok, one $2.6 \mathrm{~m}$ deep from $\mathrm{S} 2$ and one $2 \mathrm{~m}$ deep from Dome $\mathrm{C}$, all of them including triple isotopic compositions $\left(\delta^{18} \mathrm{O}, \delta^{17} \mathrm{O}\right.$ and $\left.\delta D\right)$ published in Touzeau et al. (2016). Finally, we include two snow pits from the South Pole (Jouzel et al., 1983; Whitlow et al., 1992).

\subsection{Atmospheric and snow surface monitoring}

Water vapour isotopic composition has been measured at Dome C in 2014/15 for roughly a month (Casado et al., 2016). To reduce the noise in the measurements, a running $1 \mathrm{~h}$ average was applied to the dataset. Together with water 
Table 2. Summary of the different surface snow and precipitation samplings. Precipitation samples were collected at 01:00 (UTC), when precipitation occurred. Surface snow refers to the top 5 to $30 \mathrm{~mm}$ of the firn, and subsurface snow refers to depths between 30 and $60 \mathrm{~mm}$.

\begin{tabular}{lllcll}
\hline Project & Depth/type & Years & $\begin{array}{c}\text { Sampling rate } \\
\text { (days) }\end{array}$ & $\begin{array}{l}\text { Spatial } \\
\text { distribution }\end{array}$ & Reference \\
\hline SUNITEDC & Surface & 2011 & 7 & Random & Touzeau et al. (2016) \\
PRE-REC & Precipitation & $2008-2011$ & 1 & Wooden plate & Partially in Stenni et al. (2016) \\
& Surface snow & 2012 and 2014 & 7 & Wooden plate & This study \\
\multirow{2}{*}{ NIVO } & Surface & 2013-2016 & 3 & Random & This study \\
\multirow{2}{*}{ GLACIOLOGIE } & Subsurface & Nov 2013-Jan 2014 & 1 & Random & This study \\
\hline
\end{tabular}

Table 3. Summary of the different snow pits, the respective sampling depths and vertical resolution.

\begin{tabular}{llrrrl}
\hline Station & Years & $\begin{array}{r}\text { Resolution } \\
(\mathrm{cm})\end{array}$ & $\begin{array}{r}\text { Number } \\
\text { of pits }\end{array}$ & $\begin{array}{r}\text { Depth } \\
(\mathrm{m})\end{array}$ & Reference \\
\hline Vostok & $2001-2015$ & $2-5$ & 6 & $2.5-12$ & Ekaykin and Lipenkov (2009); Ekaykin et al. (2002, 2004) \\
& $2012 / 13$ & 3 & 1 & 3.5 & Touzeau et al. (2016) \\
Kohnen & $2014 / 15$ & 3 & 2 & 3.6 & This study: Kohnen T1P1 and T2P1 \\
Dome C & $1977 / 78$ & $1-3$ & 2 & 2.3 & This study: DCoxy05 and DCoxy80 \\
& $2012 / 13$ & 3 & 1 & 3.5 & Touzeau et al. (2016) \\
& $2014 / 15$ & $1.5-5$ & 2 & 1 & This study: P09-2015 and P17-2015 \\
S2 & $2012 / 13$ & 3 & 1 & 2.6 & Touzeau et al. (2016) \\
South Pole & 1978 & 2 & 1 & 10 & Jouzel et al. (1983) \\
& $1989 / 90$ & 1.1 & 1 & 6 & Whitlow et al. (1992) \\
\end{tabular}

vapour isotopic composition monitoring, surface snow was sampled once to twice per day. During a period of $27 \mathrm{~h}$, highresolution hourly sampling of surface snow was performed to evaluate the diurnal cycle of vapour and snow isotopic composition (see Sect. 2.2).

Temperature, wind speed and humidity were performed with a $45 \mathrm{~m}$ meteorological profiling system (see Genthon et al., 2013). The temperature and humidity observations used a HMP155 ventilated thermo-hygrometers to prevent radiation bias (Genthon et al., 2011). Wind speed and direction were measured using Young 05103 and 05106 aerovanes. Snow surface temperature was measured with a Campbell scientific IR120 infrared probe located $2 \mathrm{~m}$ above the ground. The temperature reanalysis product (ERAInterim) has been compared to ventilated automatic weather station (AWS) data from Genthon et al. (2013) and we found a good agreement at the seasonal scale and fairly good agreement at the event scale $\left(R^{2}=0.89\right.$; the mean difference is $6.1^{\circ} \mathrm{C}$ and the root mean square difference is $4.8^{\circ} \mathrm{C}$ ). For this reason, all the modelling efforts realised in this paper use ERA-Interim data in order to provide a consistent quality of data through the different periods.

Snow metamorphism is difficult to quantify in the field, due to noise created by spatial variability, and requires a large number of daily samples. Therefore, we include grain index observations (Picard et al., 2012) obtained by satellite measurements using passive microwave satellite data. Pi- card et al. (2012) argue that the grain index is an indicator of the coarsening of snow grains and show its increase in summer to be anticorrelated with the integrated summer precipitation amount. Therefore, we use grain index as a proxy of the strength of the metamorphism. Whenever available, we included SSA measurements as an additional indicator of metamorphism (Libois et al., 2015; Picard et al., 2016b). Frost formation (associated with condensation) was monitored through time-lapse photography of surface hoars (see the video at https://vimeo.com/170463778) in combination with digital image processing to characterise the growth of crystals at the surface of a sastruga.

\subsection{Modelling approaches}

To investigate the impact of post-deposition processes, it is necessary to present how the surface snow isotopic composition differs from the initial precipitation signal. Because isotopic composition of the precipitation was not available for all the periods of interest, we make use of the Rayleightype Mixed Cloud Isotope Model (MCIM) (Ciais and Jouzel, 1994), which computes the Rayleigh distillation along air mass trajectories to simulate the isotopic composition of precipitation. The model includes cloud microphysical properties and accounts for mixed phase conditions. It was tuned with triple snow isotopic compositions measured along a transect from Terra Nova Bay to Dome C (Landais et al., 2008). Although supersaturation introduces large uncertain- 
ties into the model (see Jouzel and Merlivat, 1984), early work has shown that the model can successfully be tuned to overcome this limitation (Winkler, 2012). The model results, together with our new observations, provided a comparison between the spatial (estimated from observations from 10 to $1000 \mathrm{~km}$ apart) and the temporal relationships (estimated from seasonal variations) of the isotopic composition of precipitation and were used to quantify the impact of postdeposition processes by providing a reference for the precipitation isotopic composition.

\section{Results and discussions}

\subsection{Precipitation and surface snow isotopic composition time series}

\subsubsection{Precipitation isotopic composition}

In this section, we present precipitation isotopic composition data at Dome C from Stenni et al. (2016) depicting three complete annual cycles from 2008 to 2010 , completed by new data from 2011 (blue curve in Fig. 3).

At Dome $\mathrm{C}$, the isotopic composition of precipitation shows a large variability at the day-to-day scale and a regular seasonal cycle. In summer, we typically observed precipitation $\delta^{18} \mathrm{O}_{\mathrm{p}}$ above $-40 \%$ while the corresponding winter values were below $-65 \%$. At the seasonal scale, the isotopic composition of precipitation is relatively well correlated to the local temperature with a slope of $0.46 \% 0^{\circ} \mathrm{C}^{-1}$ $\left(R^{2}=0.65, n=1111\right)$, which is similar to the slope obtained by Stenni et al. (2016) for the years 2008 to 2010 of $0.49 \pm 0.02 \%{ }^{\circ} \mathrm{C}^{-1}\left(R^{2}=0.63, n=500\right)$. No lag between temperature and isotopic composition variations was observed.

Compared to other year-long precipitation time series from the East Antarctic Plateau, this slope is lower than at Dome $\mathrm{F}\left(0.78 \% 0^{\circ} \mathrm{C}^{-1}\right.$ with $R^{2}=0.78$; Fujita and Abe, 2006) and higher than at Vostok $\left(0.26 \%{ }^{\circ} \mathrm{C}^{-1}\right.$ with $R^{2}=$ 0.58; Touzeau et al., 2016). The rather wide range of slopes between precipitation isotopic composition and temperature is due to different source regions, distillation paths and local conditions such as variations between the surface temperature and the temperature inversion (Landais et al., 2012; Winkler et al., 2012), and more details are provided in Sect. 3.6.

\subsubsection{Surface snow isotopic composition}

Here, we present measurements of surface snow isotopic composition at Dome C from December 2010 to January 2016 (green curve in Fig. 3), combining results from Touzeau et al. (2016) with new data presented for the first time in this study from the PRE-REC, NIVO and GLACIOLOGIE projects. The dataset includes three complete annual cycles of surface snow isotopic composition (in 2011, 2014 and 2015) and part of the 2012 cycle, with the respective temper- ature variations and the precipitation events (from reanalysis products, ERA-Interim).

First, we focus on the impact of local spatial variability (below $1 \mathrm{~km}$ ) of the measurements. Indeed, by comparing several independent sampling campaigns in 2014, we found significant differences in the snow isotopic composition for distances ranging from 1 to $1000 \mathrm{~m}$. By comparing duplicate measurements from the NIVO campaign (taken $50 \mathrm{~m}$ apart), we found a spatial variability of surface snow isotopic composition of $3.4 \%$ for $\delta^{18} \mathrm{O}_{\mathrm{s}}$ (corresponding to 2 standard deviations, red shade in Fig. 4). Even though PRE-REC was more affected by heavy snowfalls due to the use of a wooden board, apart from a limited number of outliers (5 out of 59), the dataset is representative rather of the surface snow than the precipitation, thus providing an independent test to validate the above spatial variability. Strong differences are visible at the event scale (Fig. 4), in particular in the months of March, May and June, when the low PRE-REC values are in agreement with the isotopic composition of precipitation (Dreossi, personal communication, 2016). Excluding these outliers, the average difference between the PRE-REC and NIVO results is only $1.5 \%$, which we attribute to both spatial variability and mixture of precipitation and surface snow. Comparing the NIVO and GLACIOLOGIE datasets yields smaller differences (on average $0.4 \%$ ) but the comparison was done on a limited period without event. These independent sampling campaigns validate the confidence in an uncertainty of the surface snow $\delta^{18} \mathrm{O}_{\mathrm{s}}$ of $3.4 \%$ ( 2 standard deviations). Still, at the event scale (synoptic event of typically a couple of days), the variations of the surface snow isotopic composition exhibit an important small-scale spatial variability (difference above $5 \%$ for samples taken a few metres apart) due to the patchiness of the accumulation and snow redistribution. Caution in interpretation of variations of surface snow isotopic composition at short timescales is therefore necessary.

Second, regarding the temporal variability, data for 3 years (2011, 2014 and 2015) show a time course of temperature which is typical for the East Antarctic Plateau (see Fig. 3): a short, warm summer followed by a long, cold winter with rather constant temperature (Van Den Broeke, 1998). Superimposed on this seasonal cycle are short-lived warm events, often associated with advection of warm air masses and precipitation, particularly during the winter months due to increased storminess in the sea ice margin in this season (Papritz et al., 2014). We observed a similar pattern for $\delta^{18} \mathrm{O}_{\mathrm{s}}$ of the surface snow: annual cycles with a steep maximum centred on January (roughly a month after the temperature maximum) followed by gradual decrease during winter that is shifted by several months with respect to the air temperature. Some of the other peaks of $\delta^{18} \mathrm{O}_{\mathrm{s}}$ of surface snow may be related to warm precipitation events (Touzeau et al., 2016).

The surface snow isotopic composition was similar for all observed winters, but the summer values exhibit strong interannual variations. While the amplitude of surface snow $\delta^{18} \mathrm{O}_{\mathrm{s}}$ 


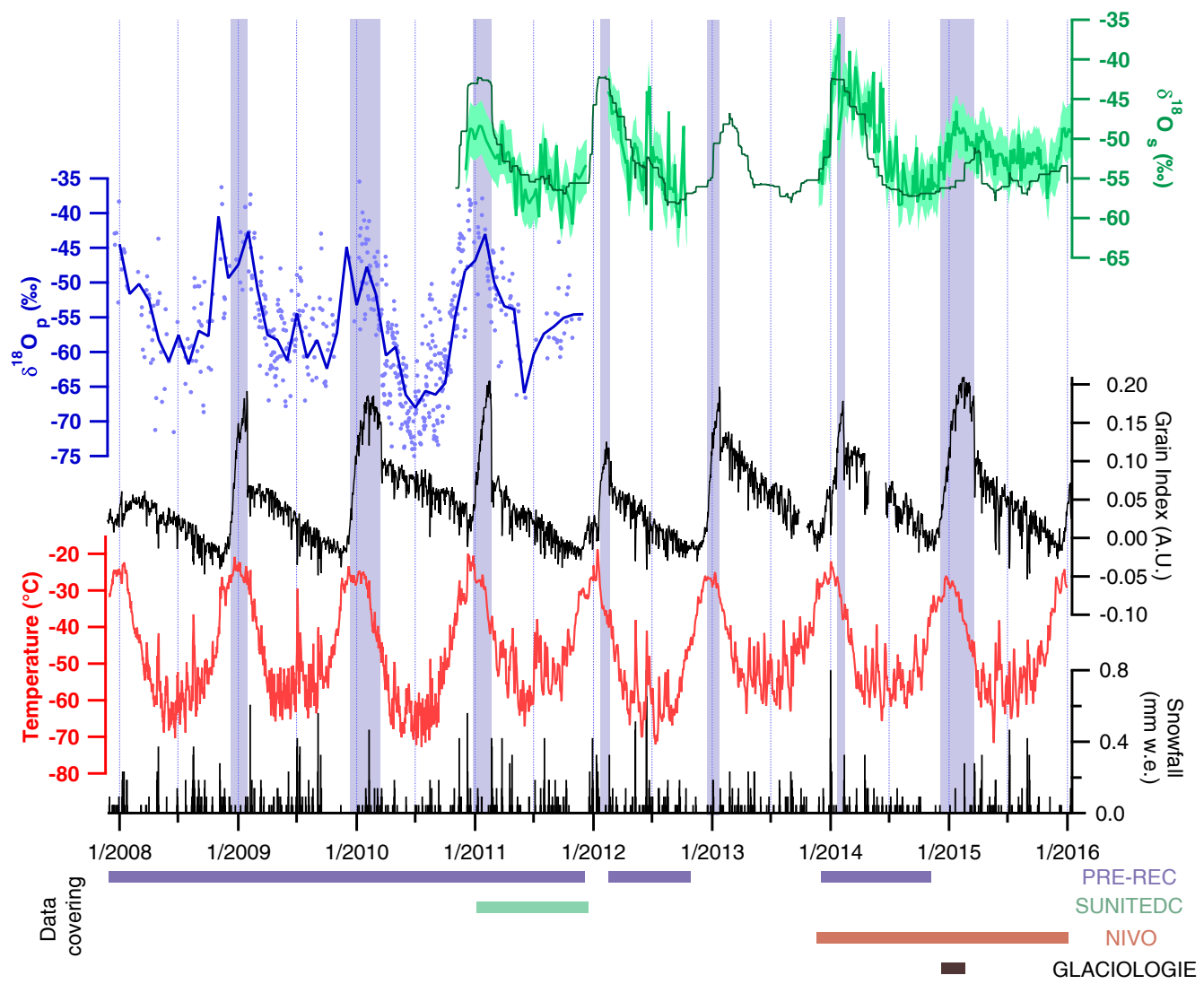

Figure 3. Monitoring of precipitation and surface snow at Dome $C$ between 2008 and 2016 (for details, see Table 2). From top to bottom: surface snow isotopic composition $\left(\delta^{18} \mathrm{O}_{\mathrm{s}}\right.$, light green lines); the light green shaded area is the uncertainty obtained from replicates ( $2 \sigma$, see Sect. 3.1.2); the dark green line is the modelled surface snow isotopic composition from the toy model detailed in Sect. 3.2; isotopic composition of precipitation $\left(\delta^{18} \mathrm{O}_{\mathrm{p}}\right.$, blue, dots: raw data, line: monthly average); grain indices from satellite observations (black fine line, Picard et al., 2012), $2 \mathrm{~m}$ temperature measurements (red line) and precipitation (black bars) from ERA-Interim reanalysis product. The blue shaded bars indicate periods of high grain index (arbitrary threshold on the variations indicating when metamorphism is active).

cycle did not exceed $10 \%$ in 2011 and 2015, in 2014 the amplitude is above $20 \%$. In 2012, despite missing data at the beginning of the year, the $\delta^{18} \mathrm{O}_{\mathrm{s}}$ variations are again more similar to 2014 with a difference of $15 \%$ in $\delta^{18} \mathrm{O}_{\mathrm{s}}$ between the maximum at the beginning of February and the minimum in September. These differences are significant with respect to the results obtained from replicate samples. Several hypotheses can be proposed to explain the variability in the summer increase of $\delta^{18} \mathrm{O}_{\mathrm{s}}$ of the surface snow: these include variability of the amount of snowfall during summer, which will be addressed in the next section, and post-deposition processes, which will be evaluated in Sect. 3.3.

\subsection{Contribution of the precipitation to the surface snow isotopic composition}

\section{Toy model description}

The large variability in the amount of snow deposited during each precipitation event can influence the surface snow $\delta^{18} \mathrm{O}_{\mathrm{s}}$ and create a different signal from that observed in the precipitation. We implemented a toy model to create synthetic precipitation isotopic composition and evaluate if the accumulation of several precipitation events captures the surface snow isotopic signal. We use the slope isotope or temperature in the precipitation $\left(0.46 \% 0^{\circ} \mathrm{C}^{-1}\right.$; Stenni et al., 2016) to create a modelled snow fall isotopic composition product from ERA-Interim temperature. The synthetic $\delta^{18} \mathrm{O}_{\mathrm{p}}$ precipitation data generated with this method conform to the amplitudes observed from 2008 to 2011 (above $-40 \%$ in summer and below $-65 \%$ in winter) as well as the warm anomalies associated with the advection of moist air masses (see Fig. A1 in Appendix A). This modelled precipitation isotopic composition can be converted to a surface snow isotopic composition by weighting the isotopic composition of each precipitation event with the amount of snow (see Appendix A).

As the snow surface samples were $1.5 \mathrm{~cm}$ thick, they contained several precipitation events (roughly the thickness in accumulation expressed in snow equivalent). Absolute values of the accumulation rate are needed to evaluate the impact of 


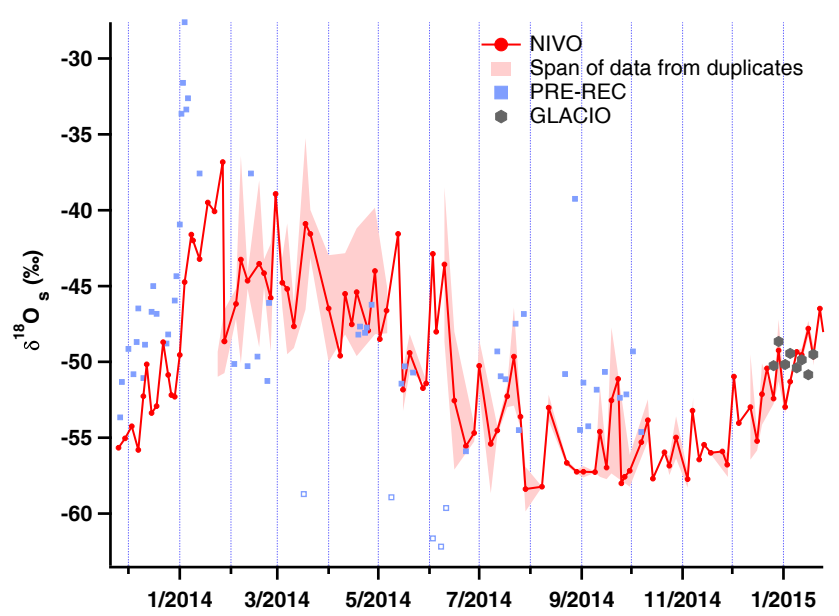

Figure 4. Comparing surface snow isotopic composition for 2014 from the NIVO dataset (red dots and line; duplicate span represented by the red shade, corresponding to the green line in Fig. 3) with measurements obtained by different campaigns: PRE-REC (blue squares) and GLACIO (grey hexagon). PRE-REC outliers are marked by unfilled squares. For details over the different campaigns' protocols, see Sect. 2.2 and Table 2.

mixing over $1.5 \mathrm{~cm}$ thickness, which is why we used renormalised precipitation estimates from ERA-Interim products to obtain the total amount of accumulation over 7 years matching the observations (Genthon et al., 2015). The results of this modelled surface snow isotopic composition are presented in Fig. 3. As described in Appendix A, the modelled surface snow isotopic composition accounts for $44 \%$ of the observed variance in the surface snow isotopic composition.

\section{Comparison with in situ observations}

We observe that the seasonal cycle of the modelled surface snow isotopic composition (dark green line in Fig. 3) is in most cases delayed compared to the temperature seasonal cycle. In particular, the summer maximum of isotopic composition is observed roughly 2 months after the temperature high. We also observe that the modelled amplitudes of these summer excursions are not regular, some presenting high amplitudes (2011, 2012 and 2014 for instance) while others are capped at values below $-50 \%$ (2015 and 2016 for instance). This is independent of the temperature seasonal cycle, which is rather regular over this period. These two features can be explained by (1) the surface snow signal, which integrates several weeks of precipitation and should thus be delayed compared to the temperature seasonal cycle, and (2) the heavy snowfalls, which are associated with warm conditions and lead to over representation of the precipitation with high isotopic composition.

The toy model described above accurately reproduced some of the differences between the signal in the surface snow and in the precipitation, including the time lag between the summer maximum of the surface snow and the precipitation. The model results may also explain why no surface snow $\delta^{18} \mathrm{O}_{\mathrm{s}}$ values below $-65 \%$ were recorded in the winter, as the cold snow events were only associated with small amounts of precipitation and did not affect the surface snow isotopic composition. However, the model did not capture the short-term variations of the surface snow isotopic composition such as the very enriched surface snow isotopic compositions in June and August 2012. There are also some discrepancies at the seasonal scale. While the model results are in good agreement with the observed winter surface snow $\delta^{18} \mathrm{O}_{\mathrm{s}}$ (with the exception of winter 2015) and 2012 and 2014 summer highs, the model performed less well for the summers 2011 and 2015. In summer 2015, the mismatch can be linked to the rather low amount of in situ precipitation (less than $0.3 \mathrm{~mm}$ w.e. from October 2014 to January 2015), which resulted in a constant modelled $\delta^{18} \mathrm{O}_{\mathrm{m}}$ until 17 February 2015, whereas on-site samples indicate an increase of the surface snow isotopic from December 2014 on.

While our toy model neglected any effects due to the wind redistribution creating the patchiness of accumulation, we expect those effects to even out at seasonal timescales due to their random nature. Therefore it cannot be the cause for the discrepancy between the persistent modelled and observed surface snow isotopic composition.

\subsection{Contribution of the exchanges between atmospheric water vapour and snow isotopic composition}

\subsubsection{Observations of a frost event}

To estimate diurnal isotopic exchanges between surface snow and atmospheric vapour, we compared measurements of atmospheric vapour isotopic composition from Casado et al. (2016) with new observations of surface snow isotopic composition obtained in parallel with the vapour monitoring during a $24 \mathrm{~h}$ period on 7 January 2015 (Fig. 5). The vapour isotopic composition was monitored at a height of $2 \mathrm{~m}$. The spatial variability of the surface snow isotopic composition was estimated from hourly triplicate sampling at one fixed and two random locations (chosen from within a $30 \mathrm{~m}^{2}$ area). The error bar presented in Fig. 5 represents the uncertainty on the surface snow due to the spatial variability and is calculated using the range of values from the three samples taken.

7 January 2015 was characterised by a large diurnal cycle amplitude in water vapour isotopic composition, humidity and temperature associated with elevated levels of turbulent and convective overturning in the atmospheric boundary layer, which in turn facilitated moisture exchanges between the snow and vapour (Casado et al., 2016). This is a common situation in summer at Dome $\mathrm{C}$ due to the weak katabatic winds. During the afternoon a frontal system appeared, affecting the air vapour isotopic composition from 06:00 (all times are UTC; the maximum of vapour isotopic composi- 


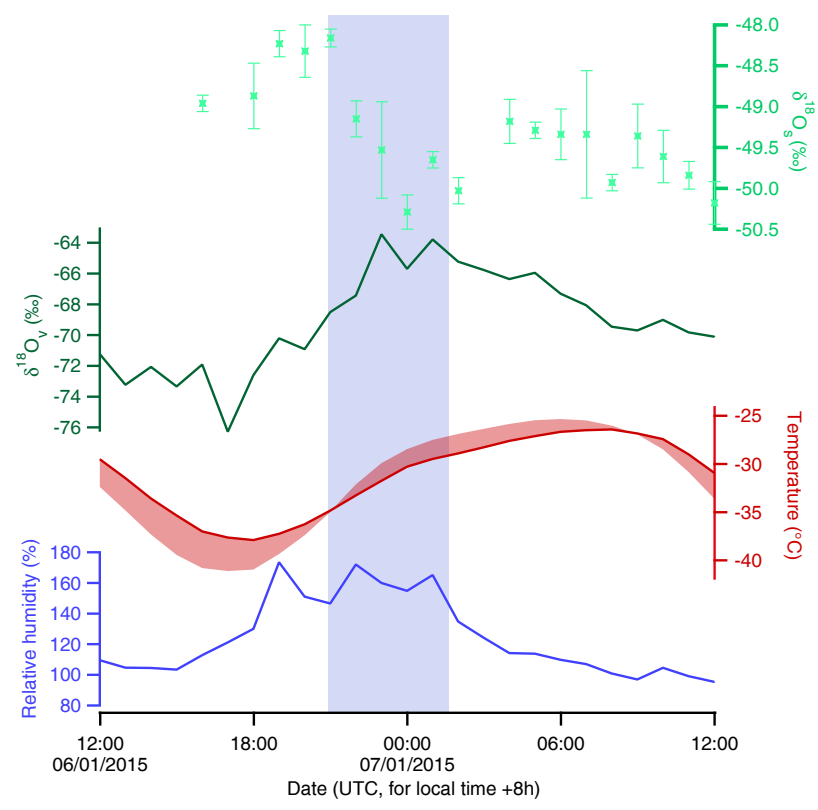

Figure 5. Isotopic composition of surface snow (light green dots, error bars are obtained from triplicates), isotopic composition of water vapour (dark green line), $3 \mathrm{~m}$ temperature (red line) compared to the surface temperature (light red shaded area) and relative humidity (blue line) during the same period from Casado et al. (2016). The blue vertical bar marks the time period during which frost was formed (see the time-lapse video: https://vimeo.com/170463778).

tion $\delta^{18} \mathrm{O}_{\mathrm{v}}$ is typically reached around $\left.06: 00\right)$. In order to be able to study the exchanges between snow and vapour while minimising the impact of meteorological events, we focused on the $11 \mathrm{~h}$ period from 18:00 on 6 January to 05:00 on 7 January 2015. From 21:00 on 6 January 2015, supersaturated conditions are observed. The supersaturated conditions may be overestimated due to the intake of microscopic snow crystal by the Picarro inlet, but other hygrometers installed at Dome $\mathrm{C}$ confirmed important supersaturated conditions with relative humidity ranging between 105 and $125 \%$ between 19:00 on 6 January and 01:00 on 7 January 2015. The wind speed and direction during this event remained constant, around $2.8 \mathrm{~m} \mathrm{~s}^{-1}$ and $165^{\circ}$. More information can be found in Casado et al. (2016).

The evolution of water vapour and snow isotopic compositions is coincident with observations of mist and solid condensation due to local supersaturation as evidenced by visual observations ( $5 \mathrm{~h}$ period in the blue shaded area in Fig. 5, see the time-lapse video in Supplement). During this $5 \mathrm{~h}$ period, water vapour $\delta^{18} \mathrm{O}_{\mathrm{v}}$ increased from -73 to $-64^{\circ}$ while snow $\delta^{18} \mathrm{O}_{\mathrm{s}}$ decreased by roughly $2^{\circ}$. Between $21: 30$ on 6 January and 01:40 on 7 January 2015, the volumes of three snow crystals were monitored by a script transferring the size in pixels of each crystals from the time-lapse sequence to surfaces using a length etalon and estimating the volume variations $\Delta V$ using a power law from the surface variations $\Delta S$ :
$\Delta V \propto \Delta S^{3 / 2}$. This showed 1.5- to 3.9 -fold increases. The crystal growth observed in the time-lapse video suggests an ice formation that was sufficient to significantly affect the isotopic composition. Solid condensation occurs simultaneously with the modification of the isotopic composition of the snow and vapour. We observe a small delay ( 2 to $3 \mathrm{~h}$ ) between the beginning of the vapour isotopic composition increase and the decrease of the surface snow isotopic composition (Fig. 5). The isotopic composition evolution is most likely due to an exchange of molecules between the snow and the vapour, significantly affecting the snow isotopic composition and leading to an enrichment of the isotopic composition of the vapour and a depletion in the snow (note that the origin of the vapour can be either from the free atmosphere or from the pores in the snow; we are not able to discriminate between the two).

\subsubsection{Thermodynamics of the isotopic exchanges between the snow and atmosphere during a frost formation in a closed box system}

We evaluated the exchanges at the diurnal scale between the atmospheric vapour and surface snow using a simple thermodynamic model. Similar to Ritter et al. (2016), we used this approach to simulate the depletion of heavy isotopes in snow and the enrichment in vapour (see above). The system consists of three boxes: (1) surface snow (roughly $1.5 \mathrm{~cm}$ thick), (2) the atmospheric box containing the atmospheric boundary layer and exchanging material with the surface and (3) the free atmosphere as a homogeneous reservoir of water vapour. The measured water vapour time series (light green in Fig. 5) characteristics correspond to the atmospheric box (2). In our approach, we realise the mass conservation at the snow-atmosphere interface. Compared to Ritter et al. (2016), the third box acts as a source to renew the air masses in the boundary layer. This conceptual model evaluates the expected variations of surface snow isotopic composition for the observed variations of water vapour isotopic composition during the frost formation. The closed box system corresponds to a case where the atmospheric box (2) cannot exchange with the free atmosphere (3), e.g. when the atmospheric boundary layer is stratified.

\section{Water vapour fluxes}

The condensation flux at the snow surface was estimated from the bulk method as about $1 \mathrm{~g} \mathrm{~m}^{-2} \mathrm{~h}^{-1}$ (Genthon et al., 2017). For the period of $5 \mathrm{~h}$ shown in blue in Fig. 5, this corresponds to a transfer of $\Delta n_{\mathrm{v}}=0.3 \mathrm{~mol} \mathrm{~m}^{-2}$ of water molecules. Considering the vapour pressure calculated from humidity monitoring during this period $\left(P_{\mathrm{v}} \approx 50 \mathrm{~Pa}\right)$, this transfer requires vapour removal from an atmospheric box height of

$h=\frac{\Delta n_{\mathrm{v}}}{P_{\mathrm{v}}} R T=12 \mathrm{~m}$, 
where $R$ is the molar gas constant and $T$ the air temperature. This height is consistent with independent estimate of the boundary layer thickness from a flux tower considering the summer dynamic of the boundary layer at Dome C (Vignon et al., 2017).

\section{Isotopic mass balance}

Now, we focus on the exchanges of water molecules differentiating the different isotopes. The calculations are done in number of molecules in order to eliminate all issues associated with the different mass of the different molecules. Isotopic composition will be expressed in ratio instead of $\delta$ values for the simplicity of the expressions. The number of moles of $\mathrm{H}_{2}^{18} \mathrm{O}$ transferred to the snow surface, $\Delta n_{\text {cond }}^{18}$, was then

$$
\Delta n_{\text {cond }}^{18}=\underbrace{\Delta n_{\mathrm{v}}^{18}}_{\begin{array}{c}
\text { Closed box like } \\
\text { contribution }
\end{array}}+\underbrace{\Delta n_{\text {ren }}^{18}}_{\begin{array}{c}
\text { Airmass } \\
\text { renewal }
\end{array}},
$$

where $\Delta n_{\text {cond }}^{18}$ is the number of molecules condensed during frost formation; $\Delta n_{\text {ren }}^{18}$ is the number of molecules renewed in the atmospheric box by either advection, molecular or turbulent diffusion; and $\Delta n_{\mathrm{v}}^{18}$ is the variation of heavy isotope molecules in the atmospheric box. Note that both the closed box contribution $\Delta n_{\mathrm{v}}^{18}$ and the renewal $\Delta n_{\text {ren }}^{18}$ are here defined as positive contributions to the total amount of heavy isotopes condensing $\Delta n_{\text {cond }}^{18}$.

First, we only consider the closed box like contribution $\Delta n_{\mathrm{v}}^{18}$. The temporal variation of the number of $\mathrm{H}_{2}^{18} \mathrm{O}$ molecules in the atmospheric box, $\Delta n_{\mathrm{v}}^{18}$ can be estimated by combining the temporal variation of the humidity content and of the isotopic ratio $R_{\mathrm{v}}^{18}$ :

$\Delta n_{\mathrm{v}}^{18}=R_{\mathrm{v}}^{18} \Delta n_{\mathrm{v}}+n_{\mathrm{v}} \Delta R_{\mathrm{v}}^{18}$.

For the case study from Sect. 3.3.1, given that we observe changes of water partial pressure of $50 \mathrm{~Pa}$ and of isotopic composition of roughly $10 \%$ (See Fig. 6), the contribution of heavy isotopes towards the surface snow in a closed box-like system is $\Delta n_{\mathrm{v}}^{18}=5.6 \times 10^{-4} \mathrm{~mol} \mathrm{~m}^{-2}$. The contribution associated with the fractionation $n_{\mathrm{v}} \Delta R_{\mathrm{v}}^{18}<5 \times 10^{-5} \mathrm{~mol} \mathrm{~m}^{-2}$ accounts for less than $10 \%$ of the contribution of the closed box system.

Second, we include the exchanges between the atmospheric box (2) and the free atmosphere (3). They cannot be directly inferred as we only measured the water vapour isotopic composition at a height of $2 \mathrm{~m}$. Due to the nighttime temperature inversion we expect mixing efficiency for the boundary layer to be low, which allowed us to parametrise this contribution by introducing a second term in $\Delta n_{\mathrm{v}}^{18}$ :

$\Delta n_{\text {ren }}^{18}=\epsilon \Delta n_{\mathrm{v}}^{18}$,

where $\epsilon$ is a parameter (varying between 0 and 1) that depends on advection and turbulence. This parametrisation is consistent with profiles of isotopic composition obtained at other stations in polar regions (Berkelhammer et al., 2016). It assumes that before the frost formation, the boundary layer was well mixed with the free atmosphere due to turbulence and convection, which in turn implies that the contribution of the free atmosphere is an input $\epsilon$ of moisture with the same isotopic composition $R_{\mathrm{v}}^{18}$ that was observed before the condensation took place.

In the complete framework, the quantity of $\mathrm{H}_{2}^{18} \mathrm{O}$ condensing $\Delta n_{\text {cond }}^{18}$, is thus defined as

$\Delta n_{\text {cond }}^{18}=\Delta n_{\mathrm{v}}^{18}+\epsilon \Delta n_{\mathrm{v}}^{18}$.

Note that this simple model is only valid for the situation where the fluxes are purely unidirectional from the atmosphere to the snow.

We apply this simple model to evaluate the variation of isotopic composition of the $1.5 \mathrm{~cm}$ of surface snow associated with the condensation of $0.3 \mathrm{~mol} \mathrm{~m}^{-2}$ of water vapour for the cases of a closed box system $(\epsilon=0 \%)$ or with the renewal of $100 \%$ of the heavy isotopes (see Fig. 6). For a closed box system $(\epsilon=0)$, the modelled variation of surface snow isotopic composition is $1.91 \%$, i.e. close to the observed value of $1.99 \pm 0.3 \%$ in the surface snow $\delta^{18} \mathrm{O}$ (Fig. 6). In the case of $100 \%$ renewal of heavy isotopes in the atmospheric box $(\epsilon=1)$, we obtain a value of $2.87 \%$, which overestimates the changes of surface snow isotopic composition.

\section{Discussion}

The box model showed that the surface snow isotopic composition at Dome $\mathrm{C}$ can be significantly affected by the formation of frost. This is in disagreement with the classical interpretation of vapour-snow isotopic equilibrium classical interpretation. Based on this typical interpretation, the solid phase should get enriched with heavy isotopes while the vapour phase should become depleted. However, our observations and modelling results appear to disagree with this approach, mainly due to the fact that the fractionation coefficients are only able to describe thermodynamic equilibrium conditions, which were not met in our case study. These in situ field results validate previous laboratory studies from Sokratov and Golubev (2009) and Ebner et al. (2017), which also showed that thermodynamic equilibrium conditions were not able to describe the exchanges between snow and vapour.

To put this into a wider context, we present other parallel measurements of vapour and snow isotopic compositions in summer in polar regions. Steen-Larsen et al. (2014) showed for NEEM station that the isotopic compositions of snow and vapour both increased by up to $7 \%$ o during warm interludes to precipitation events. Similar observations were made in Antarctica at Kohnen station (Ritter et al., 2016).

In our results, however, at the diurnal scale, no parallel evolution is observed in snow and vapour isotopic com- 

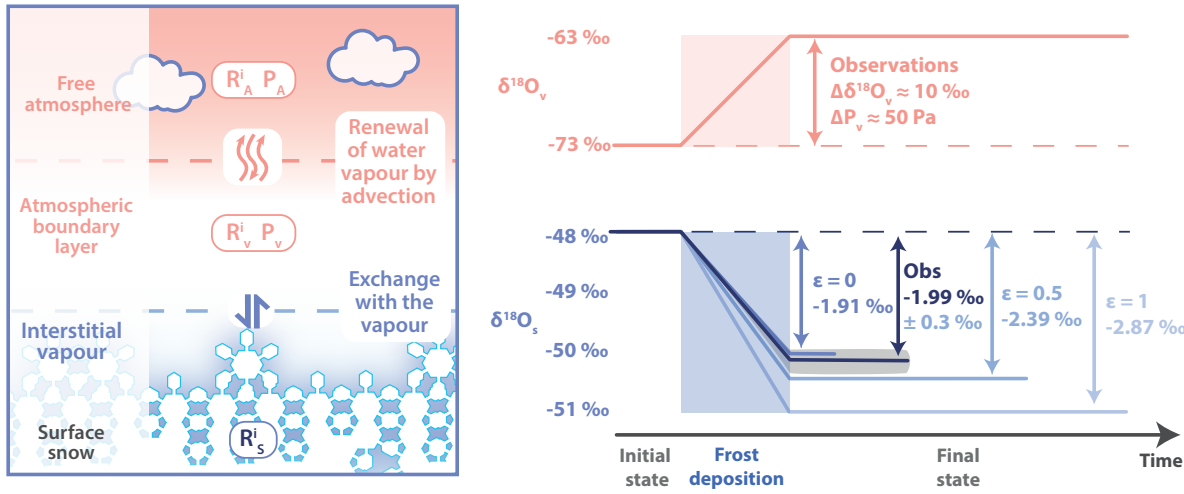

Figure 6. Schematic of the thermodynamic model to visualise exchanges between snow and vapour during condensation: the snow exchange with the vapour through equilibrium fractionation at the phase transition and the atmospheric vapour in the atmospheric boundary layer is only weakly renewed by advection of air masses ( $0 \%$ : no advection, closed box system in blue; $50 \%$ : the contribution of the advection is equal to half the amount of water vapour involved in the phase transition (purple); $100 \%$ : in orange).

positions contrasting with results from NEEM and Kohnen (Steen-Larsen et al., 2014; Ritter et al., 2016). Our observations are largely consistent with a closed system: during frost events, the vapour becomes enriched with heavy isotopes while snow is depleted. We attribute the difference to the position of the station at the top of a dome where katabatic winds are too weak $\left(3.3 \mathrm{~m} \mathrm{~s}^{-1}\right)$ to facilitate the renewal of air masses, which renders them undetectable in the snow isotopic composition. At Kohnen and NEEM, stronger winds are typically observed ( 4.5 and $4.1 \mathrm{~m} \mathrm{~s}^{-1}$, respectively), leading to a more efficient renewal of air masses, able to exchange with the surface. It is important to note that the humidity at Dome $\mathrm{C}$ is typically lower than at Kohnen and NEEM, resulting in a smaller reservoir of water vapour with which the snow can exchange. Despite these low humidity levels, a significant impact of the sublimation-condensation cycles on the snow isotopic composition is observed. Our observations are based on a single event of solid condensation and more such events need to be monitored to be able to quantitatively evaluate the fractionation processes. Because of the night-day asymmetry of the dynamic of the atmospheric boundary layer (stable at night during condensation, turbulent during the day during sublimation), we expect a more important renewal of the air masses during the day, which would lead to an anomaly of isotopic composition after several sublimation-condensation cycles.

Similar studies measuring isotopic composition of vapour and snow at sites with similar temperatures but larger wind speeds (such as at Vostok) could provide more robust insights on the impact of wind on the renewal of air masses compared to humidity levels.

\subsubsection{Evidence for isotopic modifications linked to snow metamorphism}

We use the grain index to investigate the link between snow metamorphism and surface snow isotopic composition at the seasonal scale (i.e. after a large number of successive sublimation-condensation cycles).

The grain index estimated from satellite data (Picard et al., 2012) shows periods of strong metamorphism during the summer (blue shaded areas in Fig. 3). We observed a link between high summer grain indices and the amplitude of the seasonal variation of surface snow $\delta^{18} \mathrm{O}_{\mathrm{s}}$ : in 2011 and 2015, small cycles of $\delta^{18} \mathrm{O}$ were associated with a large grain index which started to increase in December; whereas in 2014 (and partially in 2012), the large summer increase of $\delta^{18} \mathrm{O}_{\mathrm{s}}$ was associated with a small summer increase of grain index, in this case delayed until after mid-January. No such pattern was observed for precipitation (Fig. 3) whose seasonal isotopic variations appear more regular and in phase with temperature.

Picard et al. (2012) attributed high grain index values in summer to intense metamorphism (see also Libois et al., 2015), with the increase typically starting during the first week of December. Rapid decreases of the grain index result from the input of small snow grains during precipitation events. During summer 2015, we observed significant variations in the surface snow isotopic composition during periods without precipitation input (see above) and intense metamorphism as highlighted by the increase in grain index (Fig. 3). The variations of roughly $8 \%$ of $\delta^{18} \mathrm{O}_{\mathrm{s}}$ are in phase with the temperature variations. This supports the hypotheses of inputs due to the exchanges with the vapour. This is discussed more thoroughly in Sect. 3.4. Finally, the slow decrease during winter may be due to the accumulation of new small snow flakes deposited through precipitation events covering the coarse grains formed during the summer. Winter metamorphism is too slow to affect the snow structure.

The negative correlation between the amplitude of the grain index increase in summer and the amplitude of the variations of $\delta^{18} \mathrm{O}_{\mathrm{s}}\left(R^{2}=0.54\right)$ suggests that the interannual variability of the summer surface snow isotopic composition 
is directly related to the strength of metamorphism. Nevertheless, as there is a direct link between metamorphism and precipitation amount (Picard et al., 2012), the correlation between the summer surface snow isotopic composition and metamorphism could be coincidental. More samples in combination with reliable precipitation estimates are required to validate these preliminary results. The summer increase in $\delta^{18} \mathrm{O}_{\mathrm{s}}$ appeared to be rather sensitive to the summer metamorphism starting date. The high $\delta^{18} \mathrm{O}_{\mathrm{s}}$ values observed in 2014 (and probably for the year 2012, but the maximum of $\delta^{18} \mathrm{O}_{\mathrm{s}}$ was reached before the sampling started) were associated with only a small but delayed increase in grain index (black line in Fig. 3; in both cases, the main increase in grain index happened after 15 January, whereas for normal years it starts in the first week of December; Picard et al., 2012). This delayed start of metamorphism causes the surface snow to retain the enriched summer isotopic composition of precipitation. Nevertheless, a more extensive time series would be necessary to further ascertain this causal relationship. In winter, new precipitation (depleted compared to summer) was mixed with already deposited snow, as illustrated by the slow decrease of surface snow $\delta^{18} \mathrm{O}_{\mathrm{s}}$ throughout winter in a similar fashion to what was observed for the grain index. In contrast, the isotopic composition of precipitation was not affected by metamorphism, and there is thus no link between the precipitation isotopic composition and the grain index variations in Fig. 3.

\subsection{Isotopic exchanges between the surface and the subsurface snow}

During the summer 2013/14, regular sampling of surface (0$3 \mathrm{~cm}$ ) and subsurface $(3-6 \mathrm{~cm}$ ) snow (see Table 2) were carried out at Dome $\mathrm{C}$ for isotopic measurements (Fig. 7). The subsurface isotopic composition during summer 2013/14 was lower compared to the surface, which is commensurate with the results for snow pits (Sect. 3.5).

Between the end of November and mid-December, a period during which metamorphism had not started, isotopic composition values were low $(-55 \%$ ) and fairly similar between the surface and subsurface. In addition, SSA was high, which is typical of winter snow (Fig. 7). From about 16 December, large differences between the surface and the subsurface snow isotopic composition become apparent (up to $5 \%$ o higher at the surface). SSA started to decrease from about 11 December, possibly due to metamorphism. Metamorphism is also attested by grain index (see Fig. 3). On 19 December, a precipitation event occurred as attested by the increase of SSA. It is not clear whether this precipitation event was large enough to explain the observed difference between the surface and the subsurface values or whether they are linked to post-deposition processes. Before 31 December, several drift events mixed the snow and caused a high spatial variability (events observed on 10, 23, 29 December and on 1 January). A large precipitation event near 2 January

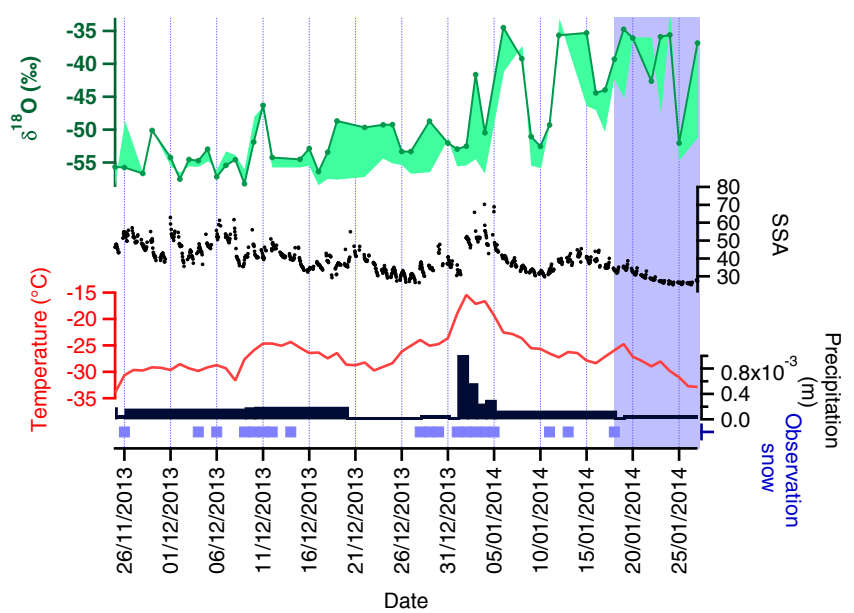

Figure 7. Comparing the surface and subsurface snow isotopic compositions at Dome C: surface isotopic composition (green line) and difference between surface and the subsurface (green shade; for more details, see Table 2); with SSA measurements (black dots), $2 \mathrm{~m}$ temperature (red line) and precipitation (black bars) from ERAInterim, as well as precipitation observations (blue squares). The vertical bar shows the period during which the grain index changes reflect large metamorphism (see Sect. 3.1.2).

is likely the cause of the $18 \%$ increase in the surface snow isotopic composition, which is mirrored in the subsurface layer about 2 days later. The associated uncertainty possibly linked to spatial variability was estimated from replicates to be about $4.8 \%$ ( 2 standard deviations), so this increase is significant. The subsurface $\delta^{18} \mathrm{O}$ increase cannot be explained by the accumulation of snow alone, as the precipitation event produced about $1 \mathrm{~cm}$ w.e. (which is already large compared to the annual accumulation of roughly $2.3 \mathrm{~cm}$ w.e.). Clearly this event mainly affected the surface snow isotopic composition while the subsurface layer only showed a delayed response.

This suggests that (1) snow metamorphism alters surface snow isotopic composition (even in the absence of precipitation) and (2) changes in surface snow isotopic composition can rapidly be transferred to the subsurface. The most likely candidate for this signal transfer is molecular diffusion across the interstitial air. However, more extensive time series are necessary to quantify the processes involved.

\subsection{Signal archived in the snow pack}

\subsubsection{Observation of apparent cycles}

At Dome $\mathrm{C}$, variations of snow isotopic composition deeper in the firn, $\delta^{18} \mathrm{O}_{N}$ are both large (of the order of $5 \%$ ) and irregular (Fig. 8). This feature has been confirmed by isotopic records from two $1 \mathrm{~m}$ deep snow pits dug in 2014/15 at Dome C (Fig. 9). The two isotopic composition profiles, 


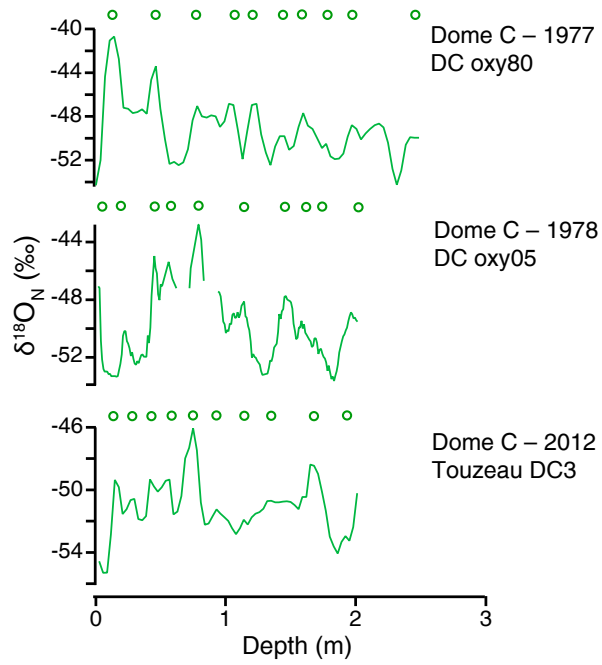

Figure 8. Isotopic composition profiles from three snow pits at Dome C; see Table 3. Successive maxima are marked with circles and indicate the pseudo-cycles for each profile. A threshold of $1.5 \%$ in $\delta^{18} \mathrm{O}_{N}$ was applied to distinguish successive local minima and maxima.

separated by about $100 \mathrm{~m}$, are uncorrelated $(R=0.15)$, as is expected from stratigraphic noise (Münch et al., 2016).

In order to evaluate whether these variations could be explained by intermittent precipitation events, and thus reflect climatic variability, we generated a profile of isotopic composition by accumulating snow using the relationship between precipitation isotopic composition and temperature, and the reanalysis products, as previously described in Sect. 3.2 and in Appendix A. The model accounted for precipitation intermittency and the temperature anomaly associated with large precipitation events. In the synthetic snow isotopic composition profiles, we observe irregular cycles characterised by minimal values (winter) of about $-55 \%$ and maximal values (summer) as high as $-42 \%$ (Fig. 9). The typical average period of these cycles is about $8 \mathrm{~cm}$, very close from the annual accumulation at Dome $\mathrm{C}(7.7 \mathrm{~cm}$ in snow equivalent, obtained using the values in Table 1 , and an average snow density of $350 \mathrm{~kg} \mathrm{~m}^{-3}$; see Table 4).

The isotopic profiles obtained from the snow pits dug in 2014/15 do not show any comparable variability and no cycle with a periodicity close to the accumulation rate (around $8 \mathrm{~cm}$ ). While the inter-peak distance in individual $\delta^{18} \mathrm{O}_{N}$ profiles varies between 10 and $40 \mathrm{~cm}$, the average spacing between $\delta^{18} \mathrm{O}_{N}$ maxima presented in both Figs. 8 and 9 is consistent across the snow pits and the value is about $20 \mathrm{~cm}$, i.e. considerably different from the expected $8 \mathrm{~cm}$. However, a power spectral density analyses of the same data yielded no discernible peaks (Laepple et al., 2018), so these $20 \mathrm{~cm}$ variations can only be referred to as "apparent cycles".
Thus, neither seasonal variability nor interannual accumulation variations explain the observed $\delta^{18} \mathrm{O}_{N}$ variability in snow pits observed at Dome C.

\subsubsection{Similarity of the apparent cycles across the East Antarctic Plateau}

By comparing our results to snow pit profiles from four other sites on the East Antarctic Plateau (Kohnen, S2, South Pole and Vostok), which are characterised by different meteorological and glaciological parameters such as mean annual temperature, elevation, wind speed and direction, accumulation or sastrugi height, we find again the same spacing on average between $\delta^{18} \mathrm{O}_{N}$ maxima (Table 4). A representative subsection of the profiles of isotopic composition from the different sites is presented in Fig. B1 in Appendix B.

This signal is particularly robust for sites such as Vostok with seven snow pits with "apparent cycle" lengths ranging from 19 and $26 \mathrm{~cm}$ and for Kohnen with 17 and $23 \mathrm{~cm}$. Similar spacings are observed for the vertical profiles of snow $\delta D_{N}$ and $\delta^{18} \mathrm{O}_{N}$. However, our manual counting method, in combination with the limited vertical resolution of certain pits, makes it difficult to attribute any statistical significance to the small differences shown in Table 4.

For high-accumulation sites such as the South Pole and Kohnen (around $20 \mathrm{~cm}$ of snow equivalent accumulation), seasonal variability should be evident in snow isotopic composition variations (Jouzel et al., 1983). In this case, the observed cycle lengths of $20 \mathrm{~cm}$ as well could simply reflect the imprint of seasonal variations in annual layers. However, profiles exhibit a high inter-site variability, even if sampled during the same year, which can be attributed to a combination of climatic signals and non-climatic noise (Fisher et al., 1985; Münch et al., 2016; Laepple et al., 2016). Profiles from the same year, but retrieved from different snow pits, do no exhibit any synchronicity in their peak patterns. As the interannual variability in precipitation should be similar across one site, the observed differences must be due to non-climatic (post-deposition) processes, smoothed by diffusion (Münch et al., 2017).

For low-accumulation sites such as Vostok and S2, results are similar to those from Dome $\mathrm{C}$ in that the spacing between $\delta^{18} \mathrm{O}_{N}$ maxima were larger than expected from the annual accumulation rates. In order to observe seasonal variations (expected length scales of 6 to $7 \mathrm{~cm}$ ), the sampling resolution would need to be $3 \mathrm{~cm}$ or finer (Nyquist, 1924; Shannon, 1949). The limited vertical resolution at $S 2$ of $3 \mathrm{~cm}$ may explain why the expected $6 \mathrm{~cm}$ seasonal cycle in isotopic composition was not found. Nonetheless, at both Vostok and Dome $\mathrm{C}$, the vertical resolution should have been sufficient to resolve the seasonal cycle and the fact that no such signal has been observed hints at other post-deposition processes (see the twin study by Laepple et al., 2018). 


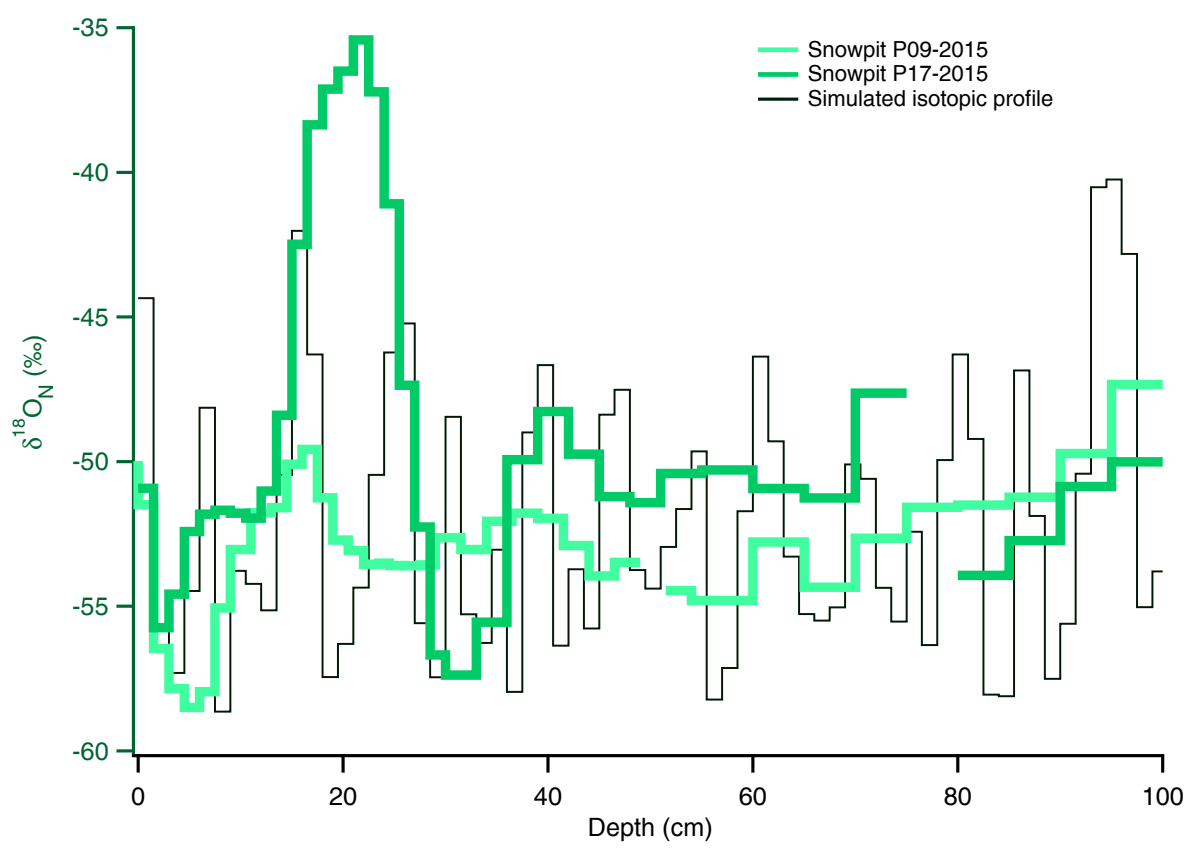

Figure 9. Comparison of two snow pit isotopic composition profiles (green lines) in January 2015 (see Table 3), with a simulated isotopic composition profile from accumulation of precipitation (dark green thin line).

Table 4. Mean "apparent cycle"; length obtained by manual counting of maxima from the isotopic composition profiles from the pits. Sites are sorted by accumulation in snow equivalent (calculated using an average snow density of $350 \mathrm{~kg} \mathrm{~m}^{-3}$ ).

\begin{tabular}{|c|c|c|c|c|c|c|}
\hline Site & $\begin{array}{r}\text { Accumulation } \\
(\mathrm{cm} \text { of snow) }\end{array}$ & $\begin{array}{c}\text { Spacing between } \\
\max \text { of } \delta^{18} \mathrm{O}_{N}(\mathrm{~cm})\end{array}$ & $\begin{array}{l}\text { Spacing between } \\
\max \text { of } \delta D_{N}(\mathrm{~cm})\end{array}$ & $\begin{array}{l}\text { Number } \\
\text { of pits }\end{array}$ & $\begin{array}{r}\text { Length of } \\
\text { the pits }(\mathrm{m})\end{array}$ & $\begin{array}{r}\text { Finest } \\
\text { resolution }(\mathrm{cm})\end{array}$ \\
\hline $\mathrm{S} 2$ & 6.0 & 24 & 20 & 1 & 2.6 & 3 \\
\hline Vostok & 6.9 & 22 & 22 & 7 & $2-12$ & 2 \\
\hline Dome C & 7.7 & 18 & 19 & 4 & $1-3$ & 1 \\
\hline Kohnen & 18.3 & 19 & NA & 2 & 3 & 3 \\
\hline South Pole & 19.7 & 20 & 20 & 2 & $6-10$ & 1.1 \\
\hline
\end{tabular}

\subsection{Implications for the relationship between isotopic composition and temperature in the precipitation and snow}

One major limitation in the temperature reconstruction from water isotopes (isotopic paleothermometer) is the uncertain and potentially variable relationship between isotopic composition and temperature. This is reflected in the range of slopes which are used to reconstruct temperature from isotopic composition including slopes obtained from precipitation at the seasonal scale, spatial slopes from samples covering several years or temporal slopes from independent calibration at large temporal scale (higher than 100 years).

Comparing the relationship between isotopic composition of precipitation and surface snow to observed and modelled temperature shows that apart from the summer months (December, January and February), the MCIM model output faithfully simulates the isotopic composition of precipitation
(Fig. 10). The modelled slope between $\delta^{18} \mathrm{O}_{\mathrm{p}}$ and temperature is $0.95 \% 0^{\circ} \mathrm{C}^{-1}$ (see Table 5), similar to the one found from the data from the transect between Terra Nova Bay and Dome $\mathrm{C}\left(1.2 \%{ }^{\circ} \mathrm{C}^{-1}\right)$ that was used to tune the model (Winkler et al., 2012). However, the slope in the precipitation observations is below $0.46 \%{ }^{\circ} \mathrm{C}^{-1}$. Strong spatial and temporal differences between the slopes of precipitation isotopic composition and temperature are to be expected (Ekaykin, 2003; Landais et al., 2012; Touzeau et al., 2016). The winter temporal slope of isotopic composition of precipitation $\left(0.76 \% 0^{\circ} \mathrm{C}^{-1}\right)$ matches the spatial slope observed on data from the East Antarctic Plateau $\left(0.77 \% 0^{\circ} \mathrm{C}^{-1}\right.$ for low isotopic composition area; Fig. 10a, Table 5). Here, because the summer isotopic composition differs from the MCIM predictions (see the December-January-February data points in Fig. 10a, slope of $0.41 \% 0^{\circ} \mathrm{C}^{-1}$ ), the slope is considerably lower for the entire year. This may be due to additional fractionation linked to re-evaporation during the precipitation 


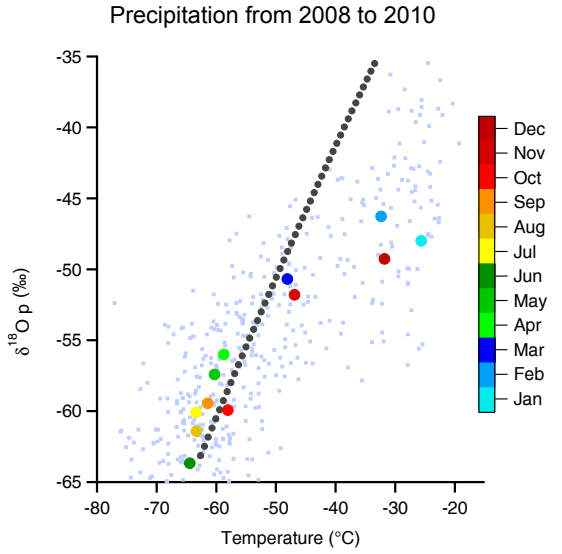

(a)

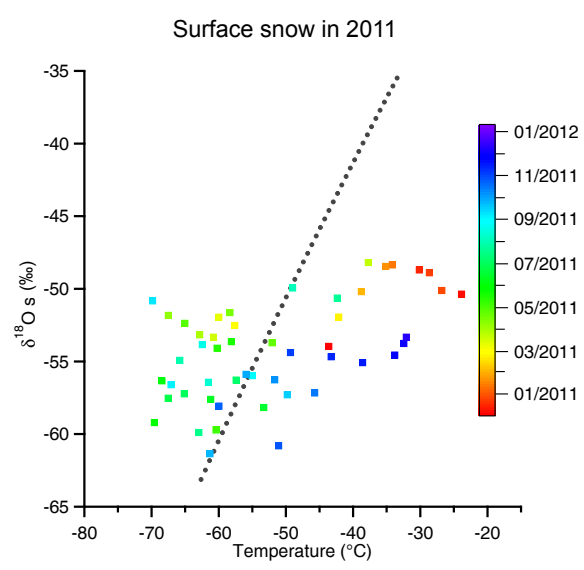

(b)

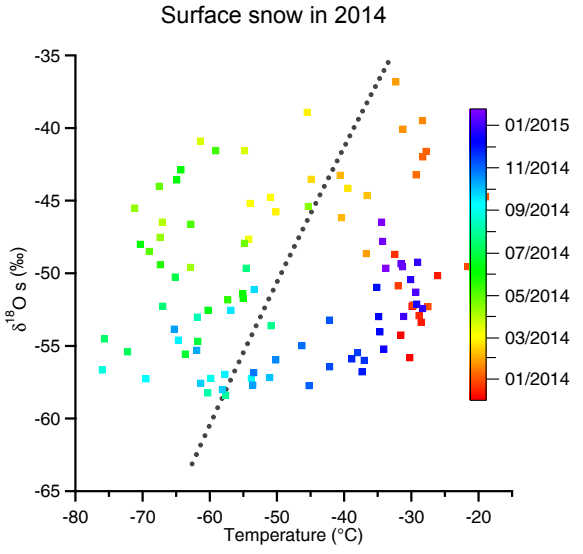

(c)

Figure 10. (a) 2008 to 2010 isotopic composition of precipitation versus temperature, showing daily averaged values from $3 \mathrm{~m}$ (light blue squares), monthly means (coloured circles) and Mixed Cloud Isotope Model (MCIM) outputs (black dotted line); panels (b) and (c) show the isotopic composition of surface snow versus daily average of $3 \mathrm{~m}$ temperature for 2011 and 2014, respectively.

events which can affect the snow flakes' isotopic composition (Koster et al., 1992) and thereby decrease the slope. Another contribution may come from changes in air mass trajectory and thus Rayleigh distillation. Back trajectory calculations for the East Antarctic Plateau indicate geographically very different moisture sources for the austral summer and winter (Sodemann and Stohl, 2009; Winkler et al., 2012). The linear relationship between condensation temperature and local surface temperature in the MCIM (Ciais and Jouzel, 1994) may be another source of error as the reduced summer temperature inversion at Dome C (Ricaud et al., 2014) is not taken into account which could lead to a reduced slope (Landais et al., 2012).

In contrast, the relationship between temperature and surface snow isotopic composition is not linear (Fig. 10). For Rayleigh-type models to be capable to evaluate the isotopic signal in deposited snow, it may be necessary to add a component that takes into account (1) the integrating effect of the snow layer accumulation and (2) the post-deposition processes. In addition, the range of surface snow isotopic composition values is not always coherent with the precipitation cycle (Fig. 10).

Because the time series of surface snow $\delta^{18} \mathrm{O}_{\mathrm{s}}$ and temperature are out of phase, the $\delta^{18} \mathrm{O}$-temperature relationship was calculated by comparing the peak to peak range in temperatures and isotopic composition. As the phase lag between surface snow $\delta^{18} \mathrm{O}_{\mathrm{s}}$ and temperature was smaller in 2011, we used that year to compare the peak-to-peak slope to results from the linear regression. In 2011, the slope between $\delta^{18} \mathrm{O}_{\mathrm{s}}$ and temperature is $0.14 \%{ }^{\circ} \mathrm{C}^{-1}$ (Touzeau et al., 2016), rising up to $0.22 \%{ }^{\circ} \mathrm{C}^{-1}$ if considering the difference between maximum summer values and minimum winter values. For 2014 , the slope was $0.49 \%{ }^{\circ} \mathrm{C}^{-1}$, lower than the prediction of the MCIM but close to the value of the slope between precipitation $\delta^{18} \mathrm{O}_{\mathrm{p}}$ and temperature reported by Touzeau et al.
Table 5. Summary of the different isotope temperature relationships observed for different datasets. Because of the 2-month shift, surface snow slopes are calculated using the difference between the extremes of isotopic composition and temperature as detailed in Sect. 3.1.2. Isotopic composition data were not sampled in summer 2012, which probably causes an underestimation of the slope. In 2011, the dephasing was sufficiently small to perform a linear regression, the result of which is shown in parentheses. The slopes for precipitation, vapour and MCIM outputs were obtained by linear regression. All correlations are significant ( $p$ values $<0.05$ ). Summer corresponds to the months from December through March, while winter from April through September.

\begin{tabular}{llrr}
\hline Type of sample & Period & $\begin{array}{r}\text { Slope } \delta^{18} \mathrm{O} \text { vs. } T \\
\left(\%{ }^{\circ} \mathrm{C}^{-1}\right)\end{array}$ & $r^{2}$ \\
\hline \multirow{3}{*}{ Surface } & 2011 & $0.22(0.14)$ & 0.29 \\
& 2012 & 0.27 & $\mathrm{NA}$ \\
& 2014 & 0.49 & NA \\
& 2015 & 0.27 & NA \\
\hline \multirow{2}{*}{ Precipitation } & All years & 0.46 & 0.65 \\
& Summer & 0.41 & 0.54 \\
Vapour & Winter & 0.76 & 0.56 \\
\hline \multirow{2}{*}{ MCIM } & Summer 2015 & 0.46 & 0.26 \\
\hline \multirow{2}{*}{ Transect to Dome $\mathrm{C}$} & Multiyear & 0.95 & 0.99 \\
& Multiyear & 1.20 & 0.69 \\
& $\delta^{18} \mathrm{O}<-40 \% 0$ & 0.77 & 0.90 \\
\hline
\end{tabular}

(2016) of $0.46 \%{ }^{\circ} \mathrm{C}^{-1}$ (see also Stenni et al., 2016, and Table 5).

In conclusion, the signal observed in the precipitation isotopic composition is only partly present in the upper few centimetres of surface snow. While averaging effects, as a result of the sampling protocol and intermittency of precipitation, are expected to impact the isotopic signal, our model sug- 
gests that they are not too small to fully explain the difference seen in the signal. We also showed that the redistribution of snow (e.g. by wind) can explain small-scale spatial and temporal variations in surface snow isotopic composition, but not at the seasonal scale. The slopes of precipitation isotopic composition versus temperature can thus not be used to reconstruct any seasonal-scale climatic signals from ice core records at Dome C.

\section{Conclusions}

This study explored post-deposition processes at the East Antarctic Plateau low-accumulation site Dome C, and how they affect the archiving of water isotopic composition from precipitation to the snow pack.

We demonstrated that atmosphere-snowpack exchanges at Dome $\mathrm{C}$ produce a seasonal signal of surface snow isotopic composition that is different from what would be expected from precipitation. The amplitude of the snow isotopic composition signal appears to be linked to the strength of surface metamorphism, a post-deposition effect that influences the relationship between $\delta^{18} \mathrm{O}$ and temperature, which in turn affects deep ice core water isotope ratios.

We also showed that depth variations in $\delta^{18} \mathrm{O}$ in shallow firn cores did not correspond to past climatic seasonal variations. The typical length scales associated with these variations or "apparent cycles" were of the order of $20 \mathrm{~cm}$ and thus significantly different from the expected seasonal cycles at these low-accumulation sites.

In addition, by plotting surface snow-precipitation isotopic composition versus temperature, we could show that the slopes obtained for surface snow differed from the slopes for precipitation, which we attributed to the different inputs that affect surface snow isotopic composition among which precipitation and various post-deposition processes.

This study qualitatively demonstrated the importance of post-deposition effects for the interpretation of isotopic signals in the surface and subsurface snow. More quantitative results could be obtained through controlled laboratory experiments, further field studies and use of snow models equipped with water isotopes. Combining several water isotopes ( $d$ excess or ${ }^{17} \mathrm{O}$ excess) may provide substantial added value due to their different relative sensitivity to equilibrium and kinetic fractionation.

Data availability. The dataset has been included in the Supplement of the manuscript. 


\section{Appendix A: Simulation of the precipitation isotopic composition}

The precipitation isotopic composition is simulated from the ERA-Interim temperature and snowfall products and the relationship between precipitation isotopic composition and temperature (Sect. 3.1.1) is given by

$\delta^{18} \mathrm{O}_{\mathrm{p}}=0.46 \times T-32$.

By comparing the simulated precipitation isotopic composition to field measurements (Fig. A1), we observe that the simulated precipitation content matches observations at the seasonal scale, except for the very low values of isotopic composition during winter. This is particularly obvious in the winter 2010 where the modelled $\delta^{18} \mathrm{O}_{\mathrm{p}}$ does not go below $-65 \%$ while observations contain several values below $-70 \%$. The simulated amplitudes only capture $85 \%$ of the observed ranges and a correlation analysis yielded $R^{2}=0.66$ $(n=500)$, which is mainly explained by the correlation of 0.63 between the temperature and the precipitation isotopic composition (see Sect. 3.1.1). The root mean square difference between the two time series is $3.5 \%$.
During winter, the modelled precipitation was able to capture the impact of high values of $\delta^{18} \mathrm{O}_{\mathrm{p}}$ associated with warm synoptic events, but not in summer.

Overall, the simulated isotopic composition signal captured most of the seasonal cycle. It was particularly successful at modelling winter temporal high $\delta^{18} \mathrm{O}_{\mathrm{p}}$ events and the phase correlation between precipitation isotopic composition and temperature.

The surface snow isotopic composition was simulated by integrating all the previous precipitation events until the width of a sample is reached (see Sect. 3.2). The modelled surface snow isotopic composition showed a correlation of $R^{2}=0.44$ between 2014 and $2016(n=181$, Fig. 3$)$. The root mean square difference between the modelled and observed isotopic composition is $2.7 \%$ o.

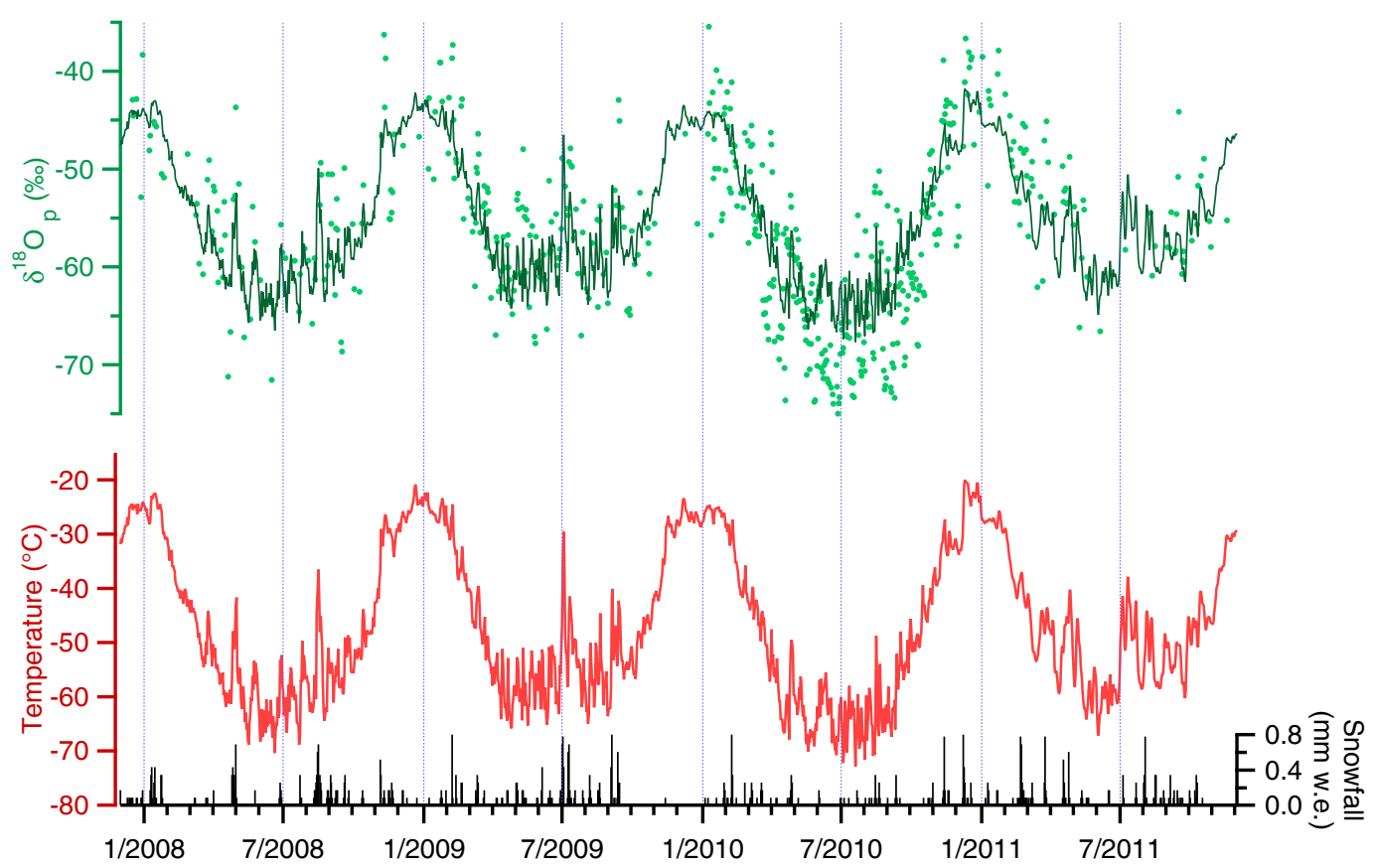

Figure A1. Comparison of isotopic composition of the precipitation (light green points) and simulated isotopic composition (dark green line) from the temperature (red) from ERA-Interim. 
Appendix B: Signal in the snow pits across the East Antarctic Plateau

We analysed variations in the snow pit data by manually counting successive local extremes, applying minimum amplitude difference of $1.5 \%$ for $\delta^{18} \mathrm{O}_{N}$ and $10 \%$ for $\delta D_{N}$. These thresholds were chosen to exceed measurements uncertainties while being lower than the expected annual variations in surface snow isotopic composition. Sensitivity tests showed the choice of the thresholds does not affect the results. For each snow pit, the mean cycle length was estimated by counting the number of maxima over the length of the pit profile. We present the average of the cycle length of the different pits for each site (Table 4).

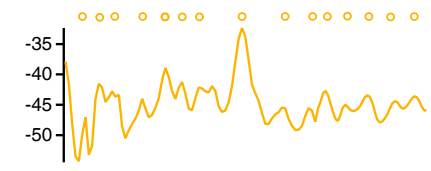

Kohnen - 2015

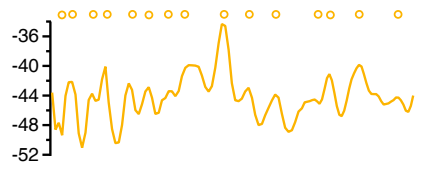

Kohnen -2015

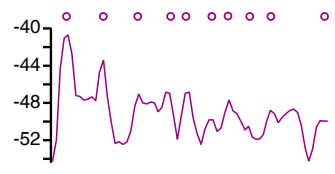

Dome C - 1977

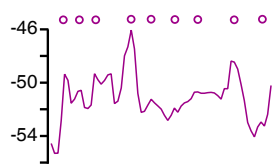

Dome C - 2012
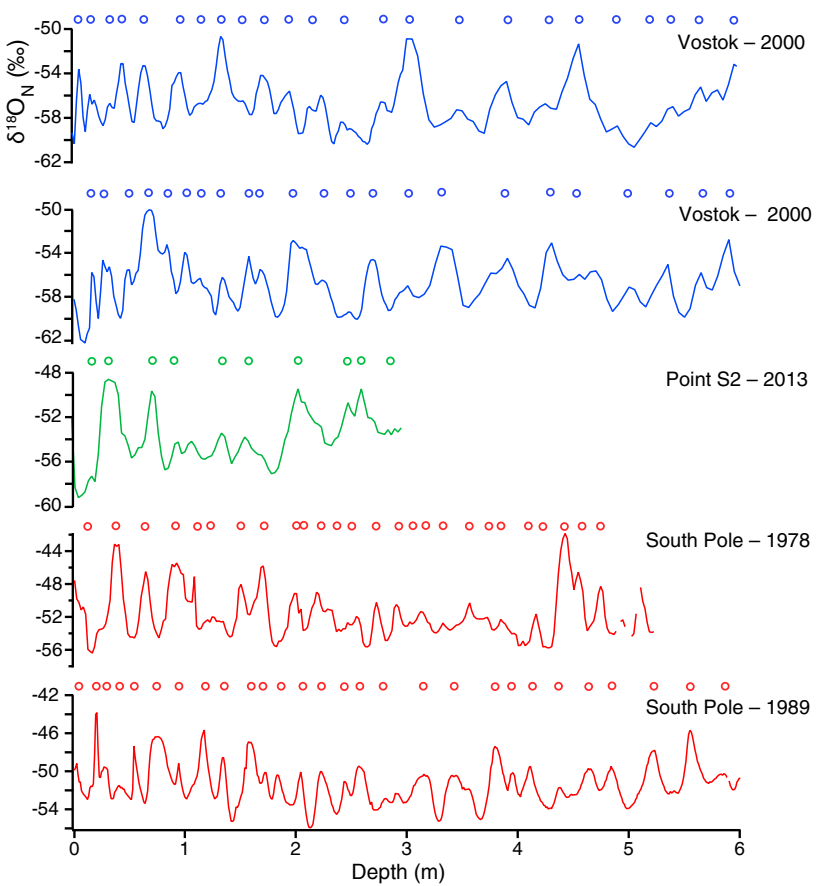

Figure B1. Isotopic composition profiles from pits $\delta^{18} \mathrm{O}_{N}$ at Kohnen (yellow), Dome C (purple), Vostok (blue), S2 (green) and South Pole (red). The circles indicate the counting of cycles for each profile using a minimal amplitude difference of $1.5 \%$. 
Author contributions. MC, AL and GP prepared the field campaigns leading to the new datasets of this paper; MC, AL, GP and LA gathered and analysed the samples of NIVO; TM and TL gathered and analysed the samples from Kohnen; BS and GD gathered and analysed the samples of PRE-REC; AE gathered and analysed the samples from Vostok; JJ gathered and analysed the samples from Dome C from the 1970s; CG and LA realised the atmospheric and snow monitoring; MC, AL, TM and TL analysed the data; all authors contributed to the discussion of the results; MC, AL and TL wrote the manuscript.

Competing interests. The authors declare that they have no conflict of interest.

Acknowledgements. The research leading to these results has received funding from the European Research Council under the European Union's Seventh Framework Programme (FP7/20072013)/RC grant agreement number 306045. These results are part of the project Antarctic-SNOW from the Foundation Albert 2 de Monaco (FA2M). Thomas Münch and Thomas Laepple were supported by the Initiative and Networking Fund of the Helmholtz Association Grant VG-NH900. We acknowledge the work of Etienne Vignon and our fruitful discussions. We acknowledge the programs NIVO, CALVA and GLACIO and all the IPEV staff that made the campaigns possible; LGGE and LIPHY for providing logistic advice and support; PNRA-PRE-REC project for the 2014 surface snow data at Concordia station. We would like to thank two anonymous referees for their careful evaluation and thoughtful comments.

Edited by: Martin Schneebeli

Reviewed by: two anonymous referees

\section{References}

Alley, R. B.: Densification and recrystallization of firn at Dome C, East Antarctica, Institute of Polar Studies, The Ohio State University, 1980.

Altnau, S., Schlosser, E., Isaksson, E., and Divine, D.: Climatic signals from 76 shallow firn cores in Dronning Maud Land, East Antarctica, The Cryosphere, 9, 925-944, https://doi.org/10.5194/tc-9-925-2015, 2015.

Baroni, M., Bard, E., Petit, J. R., Magand, O., and Bourlès, D.: Volcanic and solar activity, and atmospheric circulation influences on cosmogenic 10Be fallout at Vostok and Concordia (Antarctica) over the last 60years, Geochim. Cosmochim. Ac., 75, 71327145, https://doi.org/10.1016/j.gca.2011.09.002, 2011.

Berkelhammer, M., Noone, D. C., Steen-Larsen, H. C., Bailey, A., Cox, C. J., O’Neill, M. S., Schneider, D., Steffen, K., and White, J. W. C.: Surface-atmosphere decoupling limits accumulation at Summit, Greenland, Sci. Adv., 2, e1501704, https://doi.org/10.1126/sciadv.1501704, 2016.

Calonne, N., Geindreau, C., and Flin, F.: Macroscopic modeling of heat and water vapor transfer with phase change in dry snow based on an upscaling method: Influence of air convection, J. Geophys. Res.-Earth, 120, 2476-2497, https://doi.org/10.1002/2015JF003605, 2015.

Casado, M., Landais, A., Masson-Delmotte, V., Genthon, C., Kerstel, E., Kassi, S., Arnaud, L., Picard, G., Prie, F., Cattani, O., Steen-Larsen, H.-C., Vignon, E., and Cermak, P.: Continuous measurements of isotopic composition of water vapour on the East Antarctic Plateau, Atmos. Chem. Phys., 16, 8521-8538, https://doi.org/10.5194/acp-16-8521-2016, 2016.

Casey, K. A., Fudge, T. J., Neumann, T. A., Steig, E. J., Cavitte, M. G. P., and Blankenship, D. D.: The $1500 \mathrm{~m}$ South Pole ice core: recovering a $40 \mathrm{ka}$ environmental record, Ann. Glaciol., 55, 137146, 2014.

Ciais, P. and Jouzel, J.: Deuterium and oxygen 18 in precipitation: Isotopic model, including mixed cloud processes, J. Geophys. Res.-Atmos, 99, 16793-16803, https://doi.org/10.1029/94JD00412, 1994.

Criss, R. E.: Principles of stable isotope distribution, vol. 254, Oxford University Press, New York, 1999.

Dansgaard, W.: Stable isotopes in precipitation, Tellus, 16, 436468, https://doi.org/10.1111/j.2153-3490.1964.tb00181.x, 1964.

Delaygue, G., Jouzel, J., Masson, V., Koster, R. D., and Bard, E.: Validity of the isotopic thermometer in central Antarctica: limited impact of glacial precipitation seasonality and moisture origin, Geophys. Res. Lett., 27, 2677-2680, 2000.

Ebner, P. P., Steen-Larsen, H. C., Stenni, B., Schneebeli, M., and Steinfeld, A.: Experimental observation of transient $\delta^{18} \mathrm{O}$ interaction between snow and advective airflow under various temperature gradient conditions, The Cryosphere, 11, 1733-1743, https://doi.org/10.5194/tc-11-1733-2017, 2017.

Ekaykin, A.: Meteorological regime of central Antarctica and its role in the formation of isotope composition of snow thickness, $\mathrm{PhD}$ thesis, Geography Faculty of Saint Petersbourg, 2003.

Ekaykin, A. A. and Lipenkov, V. Y.: Formation of the ice core isotopic composition, Physics of ice core records, Low Temp. Sci., 68, 299-314, 2009.

Ekaykin, A. A., Lipenkov, V. Y., Barkov, N. I., Petit, J. R., and Masson-Delmotte, V.: Spatial and temporal variability in isotope composition of recent snow in the vicinity of Vostok station, Antarctica: implications for icecore record interpretation, Ann. Glaciol., 35, 181-186, https://doi.org/10.3189/172756402781816726, 2002.

Ekaykin, A. A., Lipenkov, V. Y., Kuzmina, I. N., Petit, J. R., Masson-Delmotte, V., and Johnsen, S. J.: The changes in isotope composition and accumulation of snow at Vostok station, East Antarctica, over the past 200 years, Ann. Glaciol., 39, 569-575, https://doi.org/10.3189/172756404781814348, 2004.

Ekaykin, A. A., Kozachek, A. V., Lipenkov, V. Y., and Shibaev, Y. A.: Multiple climate shifts in the Southern Hemisphere over the past three centuries based on central Antarctic snow pits and core studies, Ann. Glaciol., 55, 259-266, 2014.

EPICA: Eight glacial cycles from an Antarctic ice core, Nature, 429, 623-628, 2004.

EPICA: One-to-one coupling of glacial climate variability in Greenland and Antarctica, Nature, 444, 195-198, 2006.

Fisher, D. A., Reeh, N., and Clausen, H. B.: Stratigraphic noise in time series derived from ice cores, Ann. Glaciol, 7, 76-83, 1985.

Fujita, K. and Abe, O.: Stable isotopes in daily precipitation at Dome Fuji, East Antarctica, Geophys. Res. Lett., 33, L18503, https://doi.org/10.1029/2006GL026936, 2006. 
Genthon, C., Six, D., Favier, V., Lazzara, M., and Keller, L.: Atmospheric Temperature Measurement Biases on the Antarctic Plateau, J. Atmos. Ocean. Tech., 28, 1598-1605, https://doi.org/10.1175/jtech-d-11-00095.1, 2011.

Genthon, C., Six, D., Gallée, H., Grigioni, P., and Pellegrini, A.: Two years of atmospheric boundary layer observations on a $45-$ $\mathrm{m}$ tower at Dome C on the Antarctic plateau, J. Geophys. Res.Atmos., 118, 3218-3232, https://doi.org/10.1002/jgrd.50128, 2013.

Genthon, C., Six, D., Scarchilli, C., Ciardini, V., and Frezzotti, M.: Meteorological and snow accumulation gradients across Dome C, East Antarctic plateau, Int. J. Climatol., 36, 455-466, https://doi.org/10.1002/joc.4362, 2015.

Genthon, C., Piard, L., Vignon, E., Madeleine, J.-B., Casado, M., and Gallee, H.: Atmospheric moisture supersaturation in the near-surface atmosphere at Dome C, Antarctic Plateau, Atmos. Chem. Phys., 17, 691-704, https://doi.org/10.5194/acp-17-6912017, 2017.

Gkinis, V., Simonsen, S. B., Buchardt, S. L., White, J. W. C., and Vinther, B. M.: Water isotope diffusion rates from the NorthGRIP ice core for the last 16,000 years-Glaciological and paleoclimatic implications, Earth Planet. Sc. Lett., 405, 132-141, 2014.

Groot Zwaaftink, C. D., Cagnati, A., Crepaz, A., Fierz, C., Macelloni, G., Valt, M., and Lehning, M.: Event-driven deposition of snow on the Antarctic Plateau: analyzing field measurements with SNOWPACK, The Cryosphere, 7, 333-347, https://doi.org/10.5194/tc-7-333-2013, 2013.

Johnsen, S. J.: Stable isotope homogenization of polar firn and ice, in: Isotopes and impurities in snow and ice, Proceedings of the Grenoble Symposium, IAHS, 1, 210-219, 1977.

Johnsen, S. J., Clausen, H. B., Cuffey, K. M., Hoffmann, G., and Creyts, T. T.: Diffusion of stable isotopes in polar firn and ice: the isotope effect in firn diffusion, Physics of ice core records, Hokkaido University Press, Sapporo, Japan, 121-140, 2000.

Jouzel, J. and Masson-Delmotte, V.: Paleoclimates: what do we learn from deep ice cores?, WIRES Clim. Change, 1, 654-669, https://doi.org/10.1002/wcc.72, 2010.

Jouzel, J. and Merlivat, L.: Deuterium and oxygen 18 in precipitation: Modeling of the isotopic effects during snow formation, J. Geophys. Res.-Atmos., 89, 11749-11757, https://doi.org/10.1029/JD089iD07p11749, 1984.

Jouzel, J., Merlivat, L., Petit, J. R., and Lorius, C.: Climatic information over the last century deduced from a detailed isotopic record in the south pole snow, J. Geophys. Res.-Oceans, 88, 2693-2703, https://doi.org/10.1029/JC088iC04p02693, 1983.

Kawamura, K., Abe-Ouchi, A., Motoyama, H., Ageta, Y., Aoki, S., Azuma, N., Fujii, Y., Fujita, K., Fujita, S., and Fukui, K.: State dependence of climatic instability over the past 720,000 years from Antarctic ice cores and climate modeling, Sci. Adv., 3, e1600446, https://doi.org/10.1126/sciadv.1600446, 2017.

Koster, R. D., Jouzel, J., Suozzo, R. J., and Russell, G. L.: Origin of July Antarctic precipitation and its influence on deuterium content: a GCM analysis, Clim. Dynam., 7, 195-203, https://doi.org/10.1007/BF00206861, 1992.

Krinner, G., Genthon, C., and Jouzel, J.: GCM analysis of local influences on ice core delta signals, Geophys. Res. Lett., 24, 28252828, https://doi.org/10.1029/97gl52891, 1997.

Küttel, M., Steig, E. J., Ding, Q., Monaghan, A. J., and Battisti, D. S.: Seasonal climate information preserved in West Antarc- tic ice core water isotopes: relationships to temperature, largescale circulation, and sea ice, Clim. Dynam., 39, 1841-1857, https://doi.org/10.1007/s00382-012-1460-7, 2012.

Laepple, T., Hörhold, M., Münch, T., Freitag, J., Wegner, A., and Kipfstuhl, S.: Layering of surface snow and firn at Kohnen Station, Antarctica: Noise or seasonal signal?, J. Geophys. Res.Earth, 121, 1849-1860, 2016.

Laepple, T., Münch, T., Casado, M., Hoerhold, M., Landais, A., and Kipfstuhl, S.: On the similarity and apparent cycles of isotopic variations in East Antarctic snow pits, The Cryosphere, 12, 169187, https://doi.org/10.5194/tc-12-169-2018, 2018.

Landais, A., Barkan, E., and Luz, B.: Record of $\delta 180$ and 17O-excess in ice from Vostok Antarctica during the last 150,000 years, Geophys. Res. Lett., 35, L02709, https://doi.org/10.1029/2007GL032096, 2008.

Landais, A., Ekaykin, A., Barkan, E., Winkler, R., and Luz, B.: Seasonal variations of ${ }^{17} \mathrm{O}$-excess and d-excess in snow precipitation at Vostok station, East Antarctica, J. Glaciol., 58, 725-733, https://doi.org/10.3189/2012JoG11J237, 2012.

Langway, C. C.: Stratigraphic analysis of a deep ice core from Greenland, GSA Special Papers, vol. 125, Geological Society of America, https://doi.org/10.1130/SPE125, 1970.

Lazzara, M. A., Keller, L. M., Markle, T., and Gallagher, J.: Fifty-year Amundsen-Scott South Pole station surface climatology, Atmos. Res., 118, 240-259, https://doi.org/10.1016/j.atmosres.2012.06.027, 2012.

Libois, Q., Picard, G., Arnaud, L., Morin, S., and Brun, E.: Modeling the impact of snow drift on the decameterscale variability of snow properties on the Antarctic Plateau, J. Geophys. Res.-Atmos., 119, 11662-11681, https://doi.org/10.1002/2014JD022361, 2014.

Libois, Q., Picard, G., Arnaud, L., Dumont, M., Lafaysse, M., Morin, S., and Lefebvre, E.: Summertime evolution of snow specific surface area close to the surface on the Antarctic Plateau, The Cryosphere, 9, 2383-2398, https://doi.org/10.5194/tc-92383-2015, 2015.

Lorius, C., Merlivat, L., and Hagemann, R.: Variation in the mean deuterium content of precipitations in Antarctica, J. Geophys. Res., 74, 7027-7031, https://doi.org/10.1029/JC074i028p07027, 1969.

Markle, B. R., Steig, E. J., Buizert, C., Schoenemann, S. W., Bitz, C. M., Fudge, T. J., Pedro, J. B., Ding, Q., Jones, T. R., and White, J. W. C.: Global atmospheric teleconnections during Dansgaard-Oeschger events, Nat. Geosci., 10, 36-40, 2017.

Masson-Delmotte, V., Delmotte, M., Morgan, V., Etheridge, D., Van Ommen, T., Tartarin, S., and Hoffmann, G.: Recent southern Indian Ocean climate variability inferred from a Law Dome ice core: New insights for the interpretation of coastal Antarctic isotopic records, Clim. Dynam., 21, 153-166, 2003.

Morgan, V. I.: An oxygen isotope-climate record from the Law Dome, Antarctica, Clim. Change, 7, 415-426, 1985.

Münch, T., Kipfstuhl, S., Freitag, J., Meyer, H., and Laepple, T.: Regional climate signal vs. local noise: a twodimensional view of water isotopes in Antarctic firn at Kohnen Station, Dronning Maud Land, Clim. Past, 12, 1565-1581, https://doi.org/10.5194/cp-12-1565-2016, 2016.

Münch, T., Kipfstuhl, S., Freitag, J., Meyer, H., and Laepple, T.: Constraints on post-depositional isotope modifications in East Antarctic firn from analysing temporal changes of isotope pro- 
files, The Cryosphere, 11, 2175-2188, https://doi.org/10.5194/tc11-2175-2017, 2017.

NEEM Community members: Eemian interglacial reconstructed from a Greenland folded ice core, Nature, 493, 489-494, 2013.

Nicolas, J. P. and Bromwich, D. H.: New Reconstruction of Antarctic Near-Surface Temperatures: Multidecadal Trends and Reliability of Global Reanalyses, J. Climate, 27, 8070-8093, https://doi.org/10.1175/JCLI-D-13-00733.1, 2014.

North Greenland Ice Core Project members: High-resolution record of Northern Hemisphere climate extending into the last interglacial period, Nature, 431, 147-151, 2004.

Nyquist, H.: Certain Factors Affecting Telegraph Speed, Bell. Syst. Tech. J., 3, 324-346, 1924.

Oerter, H., Wilhelms, F., Jung-Rothenhäusler, F., Göktas, F., Miller, H., Graf, W., and Sommer, S.: Accumulation rates in Dronning Maud Land, Antarctica, as revealed by dielectric-profiling measurements of shallow firn cores, Ann. Glaciol., 30, 27-34, 2000.

Papritz, L., Pfahl, S., Rudeva, I., Simmonds, I., Sodemann, H., and Wernli, H.: The Role of Extratropical Cyclones and Fronts for Southern Ocean Freshwater Fluxes, J. Climate, 27, 6205-6224, https://doi.org/10.1175/JCLI-D-13-00409.1, 2014.

Petit, J. R., Jouzel, J., Pourchet, M., and Merlivat, L.: A detailed study of snow accumulation and stable isotope content in Dome C (Antarctica), J. Geophys. Res.-Oceans, 87, 4301-4308, https://doi.org/10.1029/JC087iC06p04301, 1982.

Petit, R. J., Raynaud, D., Basile, I., Chappellaz, J., Ritz, C., Delmotte, M., Legrand, M., Lorius, C., Pe, L., Petit, J. R., Jouzel, J., Raynaud, D., Barkov, N. I., Barnola, J. M., Basile, I., Bender, M., Chappellaz, J., Davis, M., Delaygue, G., Delmotte, M., Kotlyakov, V. M., Legrand, M., Lipenkov, V. Y., Lorius, C., Pepin, L., Ritz, C., Saltzman, E., and Stievenard, M.: Climate and atmospheric history of the past 420,000 years from the Vostok ice core, Antarctica, Nature, 399, 429-436, 1999.

Picard, G., Domine, F., Krinner, G., Arnaud, L., and Lefebvre, E.: Inhibition of the positive snow-albedo feedback by precipitation in interior Antarctica, Nat. Clim. Change, 2, 795-798, 2012.

Picard, G., Arnaud, L., Panel, J.-M., and Morin, S.: Design of a scanning laser meter for monitoring the spatio-temporal evolution of snow depth and its application in the Alps and in Antarctica, The Cryosphere, 10, 1495-1511, https://doi.org/10.5194/tc10-1495-2016, $2016 \mathrm{a}$.

Picard, G., Libois, Q., Arnaud, L., Verin, G., and Dumont, M.: Development and calibration of an automatic spectral albedometer to estimate near-surface snow SSA time series, The Cryosphere, 10, 1297-1316, https://doi.org/10.5194/tc-10-1297-2016, 2016 b.

Pol, K., Masson-Delmotte, V., Cattani, O., Debret, M., Falourd, S., Jouzel, J., Landais, A., Minster, B., Mudelsee, M., Schulz, M., and Stenni, B.: Climate variability features of the last interglacial in the East Antarctic EPICA Dome C ice core, Geophys. Res. Lett., 41, 4004-4012, https://doi.org/10.1002/2014GL059561, 2014.

Ricaud, P., Carminati, F., Courcoux, Y., Pellegrini, A., Attié, J.-L., El Amraoui, L., Abida, R., Genthon, C., August, T., and Warner, J.: Statistical analyses and correlation between tropospheric temperature and humidity at Dome C, Antarctica, Antarct. Sci., 26, 290-308, 2014.

Ritter, F., Steen-Larsen, H. C., Werner, M., Masson-Delmotte, V., Orsi, A., Behrens, M., Birnbaum, G., Freitag, J., Risi, C., and Kipfstuhl, S.: Isotopic exchange on the diurnal scale be- tween near-surface snow and lower atmospheric water vapor at Kohnen station, East Antarctica, The Cryosphere, 10, 16471663, https://doi.org/10.5194/tc-10-1647-2016, 2016.

Schlosser, E., Reijmer, C., Oerter, H., and Graf, W.: The influence of precipitation origin on the $\delta^{18} \mathrm{O}-\mathrm{T}$ relationship at Neumayer station, Ekströmisen, Antarctica, Ann. Glaciol., 39, 41-48, 2004.

Schmidt, G. A., LeGrande, A. N., and Hoffmann, G.: Water isotope expressions of intrinsic and forced variability in a coupled ocean/atmosphere model, J. Geophys. Res.-Atmos., 112, D10103, https://doi.org/10.1029/2006JD007781, 2007.

Shannon, C. E.: Communication in the presence of noise, Proc. IRE, 37, 10-21, 1949.

Sime, L. C., Wolff, E. W., Oliver, K. I. C., and Tindall, J. C.: Evidence for warmer interglacials in East Antarctic ice cores, Nature, 462, 342-345, 2009.

Sodemann, H. and Stohl, A.: Asymmetries in the moisture origin of Antarctic precipitation, Geophys. Res. Lett., 36, L22803, https://doi.org/10.1029/2009GL040242, 2009.

Sokratov, S. A. and Golubev, V. N.: Snow isotopic content change by sublimation, J. Glaciol., 55, 823-828, https://doi.org/10.3189/002214309790152456, 2009.

Steen-Larsen, H. C., Masson-Delmotte, V., Hirabayashi, M., Winkler, R., Satow, K., Prié, F., Bayou, N., Brun, E., Cuffey, K. M., Dahl-Jensen, D., Dumont, M., Guillevic, M., Kipfstuhl, S., Landais, A., Popp, T., Risi, C., Steffen, K., Stenni, B., and Sveinbjörnsdottír, A. E.: What controls the isotopic composition of Greenland surface snow?, Clim. Past, 10, 377-392, https://doi.org/10.5194/cp-10-377-2014, 2014.

Stenni, B., Scarchilli, C., Masson-Delmotte, V., Schlosser, E., Ciardini, V., Dreossi, G., Grigioni, P., Bonazza, M., Cagnati, A., Karlicek, D., Risi, C., Udisti, R., and Valt, M.: Threeyear monitoring of stable isotopes of precipitation at Concordia Station, East Antarctica, The Cryosphere, 10, 2415-2428, https://doi.org/10.5194/tc-10-2415-2016, 2016.

Touzeau, A., Landais, A., Stenni, B., Uemura, R., Fukui, K., Fujita, S., Guilbaud, S., Ekaykin, A., Casado, M., Barkan, E., Luz, B., Magand, O., Teste, G., Le Meur, E., Baroni, M., Savarino, J., Bourgeois, I., and Risi, C.: Acquisition of isotopic composition for surface snow in East Antarctica and the links to climatic parameters, The Cryosphere, 10, 837-852, https://doi.org/10.5194/tc-10-837-2016, 2016.

Town, M. S., Warren, S. G., Walden, V. P., and Waddington, E. D.: Effect of atmospheric water vapor on modification of stable isotopes in near-surface snow on ice sheets, J. Geophys. Res.Atmos., 113, D24303, https://doi.org/10.1029/2008JD009852, 2008.

van As, D., van den Broeke, M. R., and Helsen, M. M.: Strong-wind events and their impact on the near-surface climate at Kohnen Station on the Antarctic Plateau, Antarct. Sci., 19, 507-519, https://doi.org/10.1017/S095410200700065X, 2007.

Van Den Broeke, M. R.: The semi-annual oscillation and Antarctic climate, Part 1: Influence on near surface temperatures (195779), Antarct. Sci., 10, 175-183, 1998.

Vignon, E., van de Wiel, B. J. H., van Hooijdonk, I. G. S., Genthon, C., van der Linden, S. J. A., van Hooft, J. A., Baas, P., Maurel, W., Traullé, O., and Casasanta, G.: Stable boundary layer regimes at Dome C, Antarctica: observation and analysis, Q. J. Roy. Meteor. Soc., 143, 1241-1253, 2017. 
Vimeux, F., Masson, V., Jouzel, J., Stievenard, M., and Petit, J. R.: Glacial-interglacial changes in ocean surface conditions in the Southern Hemisphere, Nature, 398, 410-413, 1999.

Vinther, B. M., Jones, P. D., Briffa, K. R., Clausen, H. B., Andersen, K. K., Dahl-Jensen, D., and Johnsen, S. J.: Climatic signals in multiple highly resolved stable isotope records from Greenland, Quaternary Sci. Rev., 29, 522-538, https://doi.org/10.1016/j.quascirev.2009.11.002, 2010.

WAIS Divide Project members: Onset of deglacial warming in West Antarctica driven by local orbital forcing, Nature, 500, 440-444, 2013.

Wendler, G. and Kodama, Y.: On the climate of Dome C, Antarctica, in relation to its geographical setting, J. Climatol, 4, 495-508, 1984.
Whillans, I. M. and Grootes, P. M.: Isotopic diffusion in cold snow and firn, J. Geophys. Res.-Atmos., 90, 3910-3918, https://doi.org/10.1029/JD090iD02p03910, 1985.

Whitlow, S., Mayewski, P. A., and Dibb, J. E.: A comparison of major chemical species seasonal concentration and accumulation at the South Pole and Summit, Greenland, Atmos. Environ. AGen., 26, 2045-2054, 1992.

Winkler, R.: Triple-oxygen isotopic composition of meteoric waters: 17 O-excess a new tracer of the hydrological cycle, 2012.

Winkler, R., Landais, A., Sodemann, H., Dümbgen, L., Prié, F., Masson-Delmotte, V., Stenni, B., and Jouzel, J.: Deglaciation records of ${ }^{17} \mathrm{O}$-excess in East Antarctica: reliable reconstruction of oceanic normalized relative humidity from coastal sites, Clim. Past, 8, 1-16, https://doi.org/10.5194/cp-8-1-2012, 2012. 